\title{
Phylogenetic position of the acariform mites: sensitivity to homology assessment under total evidence
}

\author{
Almir R Pepato ${ }^{1 *}$, Carlos EF da Rocha', Jason A Dunlop ${ }^{2}$
}

\begin{abstract}
Background: Mites (Acari) have traditionally been treated as monophyletic, albeit composed of two major lineages: Acariformes and Parasitiformes. Yet recent studies based on morphology, molecular data, or combinations thereof, have increasingly drawn their monophyly into question. Furthermore, the usually basal (molecular) position of one or both mite lineages among the chelicerates is in conflict to their morphology, and to the widely accepted view that mites are close relatives of Ricinulei.

Results: The phylogenetic position of the acariform mites is examined through employing SSU, partial LSU sequences, and morphology from 91 chelicerate extant terminals (forty Acariformes). In a static homology framework, molecular sequences were aligned using their secondary structure as guide, whereby regions of ambiguous alignment were discarded, and pre-aligned sequences analyzed under parsimony and different mixed models in a Bayesian inference. Parsimony and Bayesian analyses led to trees largely congruent concerning infraordinal, well-supported branches, but with low support for inter-ordinal relationships. An exception is Solifugae + Acariformes (P. P $=100 \%, J .=0.91$ ). In a dynamic homology framework, two analyses were run: a standard POY analysis and an analysis constrained by secondary structure. Both analyses led to largely congruent trees; supporting a (Palpigradi (Solifugae Acariformes)) clade and Ricinulei as sister group of Tetrapulmonata with the topology (Ricinulei (Amblypygi (Uropygi Araneae))). Combined analysis with two different morphological data matrices were run in order to evaluate the impact of constraining the analysis on the recovered topology when employing secondary structure as a guide for homology establishment. The constrained combined analysis yielded two topologies similar to the exclusively molecular analysis for both morphological matrices, except for the recovery of Pedipalpi instead of the (Uropygi Araneae) clade. The standard (direct optimization) POY analysis, however, led to the recovery of trees differing in the absence of the otherwise well-supported group Solifugae + Acariformes.
\end{abstract}

Conclusions: Previous studies combining ribosomal sequences and morphology often recovered topologies similar to purely morphological analyses of Chelicerata. The apparent stability of certain clades not recovered here, like Haplocnemata and Acari, is regarded as a byproduct of the way the molecular homology was previously established using the instrumentalist approach implemented in POY. Constraining the analysis by a priori homology assessment is defended here as a way of maintaining the severity of the test when adding new data to the analysis. Although the strength of the method advocated here is keeping phylogenetic information from regions usually discarded in an exclusively static homology framework; it still has the inconvenience of being uninformative on the effect of alignment ambiguity on resampling methods of clade support estimation. Finally, putative morphological apomorphies of Solifugae + Acariformes are the reduction of the proximal cheliceral podomere, medial abutting of the leg coxae, loss of sperm nuclear membrane, and presence of differentiated germinative and secretory regions in the testis delivering their products into a common lumen.

\footnotetext{
* Correspondence: apepato@gmail.com

'Departamento de Zoologia, Instituto de Biociências, Universidade de São

Paulo, Rua do Matão, travessa 14, 321, 05508-900, São Paulo, Brazil

Full list of author information is available at the end of the article
}

(C) 2010 Pepato et al; licensee BioMed Central Ltd. This is an Open Access article distributed under the terms of the Creative Commons 


\section{Background}

Acari (mites and ticks) have been variously ranked as a group composed of one to seven or more distinct orders [1]. Together they comprise approximately half of the described arachnid diversity [2]. Two main lineages are traditionally recognized: Acariformes (or Actinotrichida) and Parasitiformes (or Anactinotrichida). Although Opiloacariformes has been regarded as a third, distinct order [3], both internal and external morphology leaves little doubt that they should be included within the Parasitiformes [4-6].

Of the two main lineages, Acariformes is the most diverse and comprises around two thirds of the known species of mites [2]. It is also an ancient group including representatives from the two of the earliest terrestrial invertebrate communities: the Rhynie Chert (Scotland) and the Gilboa Formation (New York State, USA), from the early and mid Devonian respectively. By contrast Parasitiformes appears in the fossil record only in the Mesozoic era [7] and is represented by far fewer fossil species. Among modern Acariformes, a bewildering array of lifestyles and habitats may be found and the group includes important agricultural pests, plant disease vectors, and animal parasites.

Masta and colleagues [8] explored the use of the mitochondrial genome in inferring arachnid phylogeny, but could employ data from only six of the twelve extant orders. Most of previous studies which explored chelicerate relationships included data from all orders and employed as molecular markers the nuclear ribosomal Small and Large Subunits genes (SSU and LSU rRNA, respectively) [9-11].

Initial work on the internal relationships of Acarifomes performed by one of us revealed that inclusion of many new ribosomal sequences from different acariform mites led to important changes in the topology recovered. In fact, although we agree that more genes must be included in future analysis, reducing sampling biases due to a scarcity of characters (a goal which we are pursuing), we are of the opinion that Acariformes have been largely underrepresented in previous analyses. This, together with ongoing questions about the sister group of mites, motivated the present study. Besides sampling effort, we explored the behavior of the new molecular data when analyzed alone and combined with different morphological matrices and under different analytical approaches. The aim of this was to explore possible drawbacks in the homology establishment for molecular data in previous studies.

\section{Previous studies on arachnid phylogeny and the position of acariform mites}

Weygoldt and Paulus [12] first applied the Hennigean method to arachnid phylogeny and resolved mites as the sister group of Ricinulei. They did not, however, attempt to test the monophyly of Acari since they employed the approach of coding assumed ancestral states for mites instead of scoring Acari in-group polymorphisms.

Lindquist [4] endorsed the notion of a monophyletic Acari by proposing eleven putative shared apomorphies for the clade; nevertheless most of these are mite-specific, 'tendencies' or related to size reduction [6]. Presence of a gnathosoma - i.e. a pseudotagma that includes the mouthparts - and hexapodal larvae were suggested as the main synapomorphies uniting Acari and Ricinulei.

Hammen [13,14] regarded the presence of a gnathosoma in Acari and Ricinulei as non-homologous based on details of gnathosoma morphology; particularly the insertion positions of its musculature. Acariformes was hypothesized to be sister group of Palpigradi (together forming his Epimerata group) and Anactinothrichida the sister group of Ricinulei (his Cryptognomae group). Even though Hammen performed an extensive survey of mite and arachnid morphology, his rejection of cladistics and his controversial scenario of leg coxa evolution in support of Epimerata have lessened the impact of his conclusions.

The phylogenetic analysis performed by Shultz $[15,16]$ again recovered mites as sister group of Ricinulei. This clade was formally named Acaromorpha, although Dubinin [17] coined this name earlier, referring to mites only. Shultz $[15,16]$ performed his analyses after an extensive survey of characters - particularly those relating to appendage musculature - but like Weygoldt and Paulus [12] used supraspecific terminal taxa to code characters. Therefore, he did not test mite monophyly. Nevertheless, the notion of a monophyletic Acari and its inclusion in Acaromorpha sensu Shultz has received increasing acceptance among the acarological and arachnological communities. However, it should be reiterated that no new evidence for this clade in terms of explicit synapomorphies has been brought to light since the summary of Lindquist [4].

Wheeler and Hayashi [9] analyzed partial SSU and LSU rRNA sequences from species belonging to all arachnid orders except Palpigradi and recovered a diphyletic Acari in their molecular analysis. Whereas the single Acariformes species included, Tetranychus urticae, was recovered in an unlikely position at the base of the cladogram outside the other Chelicerata, Parasitiformes emerged in this analysis as the sister group of Pycnogonida (sea spiders). One should bear in mind, that this analysis must be regarded as a first attempt, including few terminals. No molecular data on the order Palpigradi, for example, could be included. When combining morphological and molecular data a cladogram quite similar to that obtained by Shultz's [16] 
morphological analysis was recovered; the 'total evidence' analysis differing primarily from Shultz's results in its placement of Amblypygi (whip spiders).

The Acaromorpha hypothesis has been challenged by observations from paleontology and ultrastructure. Dunlop [18], supplemented by Dunlop et al. [19], presented a set of putative apomorphies linking Ricinulei to the fossil order Trigonotarbida, which would imply that the presence of a "gnathosoma" in Ricinulei is homoplastic. An analogous scenario had been already proposed by Hammen [20].

Alberti and Peretti [21] confirmed previous observations on Solifugae sperm cells (absence of a carioteca in mature spermatozoa) and on testis structure (presence of differentiated germinative and secretory regions delivering their products into a common lumen). They argued that these observations should be considered as putative apomorphies shared between Solifugae and Acariformes to the exclusion of the Parasitiformes mites.

Giribet et al. [10] employed a broader taxon sampling than Wheeler and Hayashi [9], including molecular data from all arachnid orders. In addition, they employed a species exemplar approach for coding the morphological characters, reflecting in the analysis the morphological diversity of the orders, which allows at the same time a test of their monophyly. In the molecular analysis, mites again appear as diphyletic, with Acariformes as a basal group and Parasitiformes here as the sister group of Pseudoscorpiones. The combined analysis of neontological data recovered a monophyletic Acari, but resolved them as a basal lineage far from Ricinulei. When adding fossils and rooting the tree on Trilobita, Ricinulei formed a clade with the fossil order Trigonotarbida; together as sister group of Tetrapulmonata (Araneae, Uropygi and Amblypygi). In this analysis, a monophyletic Acari came out as sister-group of Pycnogonida. Note, however, that both the neontological and paleontological trees are quite similar. If the paleontological tree was rooted on Pycnogonida the resulting topology would be similar to that obtained for the neontological data alone; although with Trilobita as the sister group of Xiphosura.

In an article focusing on Parasitiformes phylogeny, Klompen et al. [11] also included seven Acariformes species: three Prostigmata, three Oribatida and one Endeostigmata. Klompen et al. [11] employed a methodology completely different from previous molecular studies. Instead of direct optimization as implemented in the program POY, they used the secondary structure as a guide for hypothesizing the nucleotide homology (alignment) and applied parsimony and Bayesian analyses. The results obtained are well supported for Parasitiformes relationships, but lack resolution for the Arachnida orders. They recovered mites as a monophylum, but resolved no clear hypothesis with respect to the mites' sister-group. The Acaromorpha hypothesis required the addiction of 14 steps to the MPTs recovered in their parsimony analysis.

In his latest arachnid study, Shultz [22] offered a thorough revision of arachnid morphology and employed the species exemplar approach for coding characters, i.e. reflecting taxon polymorphism. Acaromorpha was recovered again, but with low support and, when fossils were included, Acari became diphyletic and Ricinulei were recovered as sister group of Parasitiformes only. Concerning mites' relationships, the results of this analysis should be interpreted with caution. Although Shultz cited the article by Alberti and Peretti [21], he did not take into consideration the main reasons which led them to question the association of Solifugae and Pseudoscorpiones (the clade Haplocnemata): namely their testis and spermatozoa structure. Shultz also misinterpreted Alberti and Peretti [21] when evaluating alternative phylogenetic relationships. He stated that these authors clustered both mite lineages with Solifugae (see his figure three), whereas Alberti and Peretti actually proposed that only Acariformes should be related to Solifugae. Finally, some differences among the two main lineages of mites, such as the condition of the sternal region were not correctly scored (for a summary of these differences we refer the reader to $[5,6])$.

The position and monophyly of Acari has occasionally been tested in larger studies of arthropod phylogeny in general; although we would caution here that the number of mite taxa included as terminals was usually rather small. Regier et al. [23] produced the most comprehensive and up to date molecular phylogeny for arthropods in general, with 62 genes tested for 80 taxa, whereby acariform and parasitiform mites were both represented here by single exemplars (Dinothrombium and Amblyomma respectively). Within a monophyletic Arachnida, Parasitiformes was recovered as the sister group of Pseudoscorpiones (as per Giribet et al. [10]) with Opiliones as their outgroup. Acariformes was recovered as the sister group of Palpigradi (essentially Hammen's Epimerata hypothesis $[13,14]$ ); this clade being basal with respect to all other arachnids.

Finally, in a recent publication Dabert et al. [24] investigated Acariformes phylogeny using $18 \mathrm{~S}$ rDNA and mitochondrial cytochrome oxidase subunit I tested across 142 acariform species, plus 34 outgroups. They recovered Acariformes as monophyletic with the traditional split into Trombidiformes and Sarcoptiformes, and for the sarcoptiform mites they provided molecular support for an emerging hypothesis that Oribatida is paraphyletic with respect to Astigmata - the astigmatans being the sister group of a derived oribatid lineage. Age estimates for splits into the major groups were also 
calculated; with acariform mites estimated as having their origins in the Silurian (ca. $430 \mathrm{Ma}$ ), which is broadly consistent with the fossil record (see above). Acari was again recovered as diphyletic. Parasitiformes resolved as the sister group of Pseudoscorpiones, a similar result to that of Giribet et al. [10] and Regier et al. [23]. Significantly, Acariformes resolved in Dabert et al.'s study as sister group to Solifugae, and with good support. Here, we present further evidence for this hypothesis based on combined morphological and molecular data. We also suggest a formal name for this putative clade encompassing acariform mites and camel spiders.

\section{Methods}

\section{Taxa sampled}

We follow Giribet and Ribera [25] in considering Pycnogonida as an appropriate out-group for rooting the resulting tree. Despite Maxmen et al.'s [26] hypothesis for the protocerebral nature of the pycnogonid chelifores and the defence of the traditional view of tritocerebral chelicerae by Bitsch and Bitsch [27], data from gene expression and neuroanatomical studies convincingly demonstrate that chelifores, chelicerae and mandibulate antennae are homologous, deutocerebral elements [28-31]. Despite its long list of autapomorphies, Pycnogonida 'chelifores' are considered here to be true chelicerae, thus providing morphological support for sea spiders' placement as sister-group of Euchelicerata.

Representatives from all euchelicerate orders were sampled here, comprising 91 terminal taxa, of which 40 are acariform mites. Among them, one palpigrade, one whip spider, three spiders and 32 actinotrichid mites are newly sequenced. Since a formal cladistic analysis including Acariformes lineages is unavailable, we used the dendrograms summarized in Norton et al., [32] as a reference for the sampling design. We tried to include representatives of all major lineages of Acariformes. Table 1 and Fig. 1 summarize the sampling effort. Following the latest account of Acari classification [33], Endeostigmata was retained, although it certainly is not a monophylum [34]. Furthermore, the assignment of the rank Superorder to Acariformes and Parasitiformes is retained, although it certainly does not agree with the current classification of Chelicerata; i.e. 'Superorders' are rarely used for arachnids other than mites.

\section{DNA extraction, vouchering, amplification and sequencing}

Individual body parts, such as a leg article, or entire specimens were used for genomic DNA extraction. When the entire specimen was destroyed by the extraction process, individuals from the same population were kept as vouchers. Voucher material is deposited in the Museu de Zoologia da Universidade de São Paulo (MZSP) and its collection numbers are provided in the additional file 1 along with details on sampling locality.

Small pieces of animal tissue (less than $0.5 \mathrm{~mm}$ ) for large arachnids or the entire animal for many mites were crushed against the vial wall and mixed with a small water volume. Chelex based solution Instagene ${ }^{\circ}$ (BIORAD) was added to the vial and incubated for 30 $\min$ at $54^{\circ} \mathrm{C}$, followed by $8 \mathrm{~min}$ at $100^{\circ} \mathrm{C}$. The solution was spun and approximately $140 \mu$ of supernatant, in most cases, enough for 14 PCR reactions, was obtained.

The SSU rRNA genes were amplified and sequenced using the three pairs of primers described in Giribet et al. [35], or with the intermediary segment pair replaced by the 18SV4F-18SV4R primer designed by Otto \& Wilson [36]. For the $28 \mathrm{~S} \mathrm{D} 3$ region we used the primer pair 28SA-28SB described in Whiting et al. [37].

Amplification was carried out in a $25 \mu \mathrm{l}$ volume with 0.6 units of Taq Polymerase (Fermentas), $100.00 \mu \mathrm{M}$ of DNTPs, $2.50 \mathrm{mM}$ of $\mathrm{MgCl}_{2}$ and $0.40 \mu \mathrm{M}$ of each primer. The thermocycler program included an initial denaturing step of $4 \mathrm{~min}$. at $94^{\circ} \mathrm{C}$, and 35 amplification cycles of $30 \mathrm{~s}$. of denaturing at $94^{\circ} \mathrm{C}, 30 \mathrm{~s}$ of annealing at $50^{\circ} \mathrm{C}, 45 \mathrm{~s}-1 \mathrm{~min}$ of extension at $72^{\circ} \mathrm{C}$ and a final step of extension of $5 \mathrm{~min}$. at $72^{\circ} \mathrm{C}$. The PCR products were purified using the Ampure ${ }^{\circ}$ (Agencourt) kit and sequenced using an ABI Prism 3100 Genetic Analyzer Sequencer. Cycle-sequencing with AmpliTaq DNA polymerase, FS (Perkin-Elmer) using dye-labeled terminators (ABI Prism BigDye Terminator CycleSequencing Ready Reaction Kit) was carried out in a $10 \mu \mathrm{l}$ volume of reaction: $4 \mu \mathrm{l}$ of Terminator Ready Reaction Mix, 10-30 ng/ $\mathrm{ml}$ of PCR product, $5 \mathrm{pmol}$ of primer, and $\mathrm{dH} 2 \mathrm{O}$ to $10 \mu \mathrm{l}$. The cycle-sequencing program consisted of an initial step at $94^{\circ} \mathrm{C}$ for $3 \mathrm{~min}, 25$ sequencing cycles $\left(94^{\circ} \mathrm{C}\right.$ for $10 \mathrm{~s}, 50^{\circ} \mathrm{C}$ for $5 \mathrm{~s}, 60^{\circ} \mathrm{C}$ for $\left.4 \mathrm{~min}\right)$. The BigDye-labeled PCR products were isopropanol-precipitated following the manufacturer's protocol.

Reverse and direct chromatograms were assembled using the program ChromasPro 1.41 (Technelysium Pty Ltd).

\section{Analyses}

Ribosomal RNA is the core of this organelle's function. It is the target of intense stabilizing selection in order to maintain its catalytical activity. However, this activity is more related to its secondary and tertiary structure, constructed by the correct pairing of RNA nucleotides, than to its nucleotide composition.

Inside stems, a mutation that disturbs the correct base pairing is likely to reduce molecular fitness. A compensatory mutation that re-sets a normal pairing is favored by the selection, replacing one Watson-Crick pairing 
Table 1 Chelicerate non-Actinotrichida included in the analysis

\begin{tabular}{|c|c|c|c|c|c|c|c|c|}
\hline Species & SSU rRNA & $\begin{array}{l}\text { LSU D3 } \\
\text { rRNA }\end{array}$ & Species & $\begin{array}{l}\text { SSU } \\
\text { rRNA }\end{array}$ & $\begin{array}{l}\text { LSU D3 } \\
\text { rRNA }\end{array}$ & Species & SSU rRNA & $\begin{array}{l}\text { LSU D3 } \\
\text { rRNA }\end{array}$ \\
\hline Class Pycnogonida & & & Order Ricinulei & & & $\begin{array}{l}\text { Neobisium } \\
\text { polonicum }\end{array}$ & EU559357 & EU559457 \\
\hline Achelia echinata & AF005438 & AF005459 & Pseudocellus pearsei & U91489 & AF124956 & $\begin{array}{l}\text { Anagarypus } \\
\text { heatwolei }\end{array}$ & EU559376 & EU559482 \\
\hline Callipallene sp. & AF005439 & AF005460 & Ricinoididae sp & AF124930 & AF062988 & Americhernes sp. & AF124934 & AF062982 \\
\hline Endeis laevis & AF005441 & AF005462 & Order Opiliones & & & Order Araneae & & \\
\hline Colossendeis C & AF005440 & AF005461 & Siro rubens & U36998 & U91494 & $\begin{array}{l}\text { Liphistius } \\
\text { bicoloripes }\end{array}$ & AF007104 & AF124960 \\
\hline Class Chelicerata & & & Stylocellus sp. & AF173419 & Af173422 & Aphonopelma sp. & X13457 & - - \\
\hline Order Xiphosura & & & Odiellus troguloides & X81441 & U91500 & Atypoides riversi & DQ981699 & DQ639855 \\
\hline Limulus polyphemus & U91490 & U91492 & Pachyloides thorellii & U37007 & U91508 & Nesticus celullanus & AF005447 & AF124961 \\
\hline $\begin{array}{l}\text { Carcinoscorpius } \\
\text { rotundicauda }\end{array}$ & U91491 & U91493 & Caddo agilis & U91487 & U91502 & Lyssomanes viridis & DQ665742 & - \\
\hline Order Schizomida & & & Sabacon cavicolens & AF124944 & AF124972 & Tetragnathidae & HM070337 & HM07300 \\
\hline Stenochrus portoricensis & AF005444 & -二-二 & Leiobunum sp. & AF124940 & AF124968 & Corinnidae & HM070338 & HM07301 \\
\hline Trithyreus pentapeltis & AF124932 & AF062990 & $\begin{array}{l}\text { Nemastoma } \\
\text { bimaculatum }\end{array}$ & AF124947 & AF124974 & Pholcidae & HM070339 & HM07302 \\
\hline Order Thelyphonida & & & Zuma acuta & AF124951 & AF124978 & Order Solifugae & & \\
\hline Mastigoproctus giganteus & AF005446 & AF062989 & $\begin{array}{l}\text { Supeorder } \\
\text { Parasitiformes }\end{array}$ & & & Gluvia dorsalis & AF007103 & AF124957 \\
\hline Order Amblypygi & & & Opilioacarus texanus & AF124935 & AF124963 & $\begin{array}{l}\text { Eusimonia } \\
\text { wunderlichi }\end{array}$ & U29492 & AF124958 \\
\hline Paraphrynus sp. & AF005445 & AF124959 & $\begin{array}{l}\text { Amblyomma } \\
\text { americanum }\end{array}$ & AF291874 & AF291874 & Chanbria regalis & AF124931 & AF062983 \\
\hline Amblypygi sp. & AF124933 & AF062965 & Otobios megnini & L76356 & - - & Eremobates sp. & AY859573 & AY859572 \\
\hline Musicodamon atlanteus & AY829903 & AY829924 & $\begin{array}{l}\text { Allothyrus of } \\
\text { australasiae }\end{array}$ & AY620910 & AY626628 & $\begin{array}{l}\text { Order } \\
\text { Scorpiones }\end{array}$ & & \\
\hline Charinus montanus & HM070335 & HM07298 & Sternothyrus braueri & AY620912 & AY626630 & $\begin{array}{l}\text { Pandinus } \\
\text { imperator }\end{array}$ & AY210831 & AY156537 \\
\hline Order Palpigradi & & & $\begin{array}{l}\text { Order } \\
\text { Pseudoscorpiones }\end{array}$ & & & Belisarius xambeui & AF005442 & AF124954 \\
\hline Eukoenenia n. sp. & AF207648 & AF207653 & Chthonius sp. & EU559387 & EU559438 & $\begin{array}{l}\text { Androctonus } \\
\text { australis }\end{array}$ & X77908 & AF124955 \\
\hline Eukonenia sp. & HM070336 & HM07299 & Pseudogarypus bicornis & EU559368 & EU559472 & & & \\
\hline
\end{tabular}

Species sampled and Genbank accession numbers of non-Acariformes taxa

for another or for slightly less stable guanine and uracile pairs [38]. Pairing between adenine and cytosine is much rarer but may have a similar effect if protonated, since they are geometrically similar to the G:U, U:G pairs [39].

This property of ribosomal gene evolution may therefore be a tool for assessing nucleotide homology. Detection of compensatory or semi-compensatory mutations along a multiple alignment is the main tool employed for inferring ribosomal RNA secondary and tertiary structures $[38,40]$, and has been largely confirmed by crystallographic results [41].

The secondary structure alignment was made employing the method described by Kjer [42], except for employing the program BioEdit 7.0.9 [43] for sequence editing. Template SSU rRNA structures were downloaded from the "European Ribosomal DataBase" [44].
Template LSU structures were obtained from Schnare et al. [45]. For both genes, the secondary structures inferred by Rix et al. [46] were also valuable.

For regions where the nucleotide composition does not readily allow the detection of correspondence to the models, potential pairings was explored using Mfold [47]. Alignments were produced first for each of the orders using compensatory mutations and similarity as criteria. After this step, common structural motifs were used to align the entire data set. Consensus secondary structures for these alignments were inferred using the program RNAalifold [48]. Only nucleotides in regions whose alignments were sustained by compensatory mutations across the entire data set were considered as homologous. Regions inferred to be ambiguously aligned were classified following Gillespie [49] in regions of expansion and contraction (REC), non-pairing regions of 


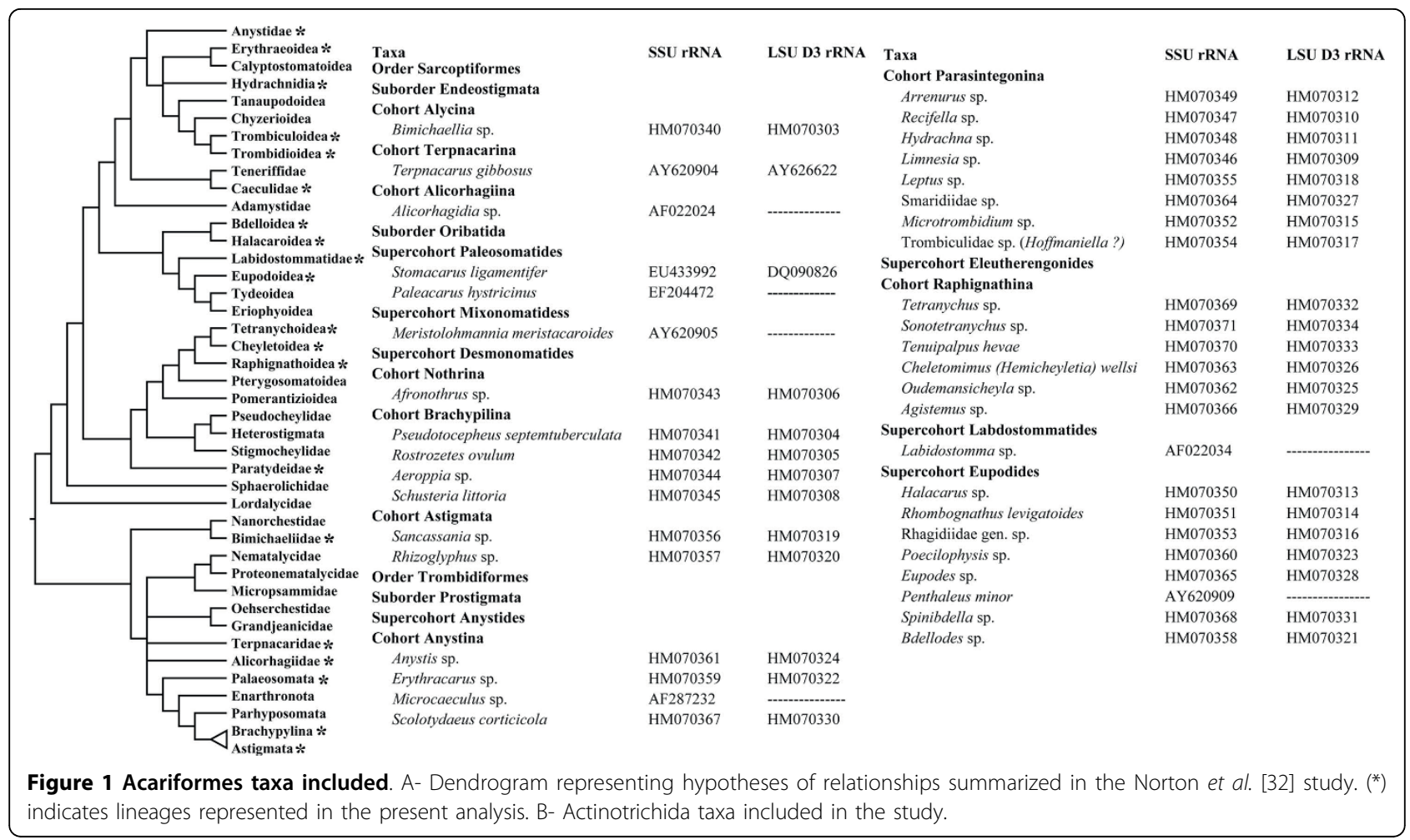

ambiguous alignment (RAA) and regions of slippedstrand compensation (RSC). The structural models for exemplar species are presented in the results section using the Wuyts et al. [44] notation for SSU rRNA and Cannone et al. [50] for LSU. The figures displaying secondary structure features were drawn using the xRNA program (developed by B. Weiser and H. Noller, University of Santa Cruz).

Fasta files containing the alignment labeled with the SSU and LSU rRNA secondary structure are included in the digital supplementary material associated with this article (additional file 2).

\section{Bayesian phylogenetic inference}

Wheeler and Honeycutt [51] demonstrated that stem and loop regions may point to different phylogenies. This is to be expected since compensatory mutations violate the assumption of character independence made by parsimony and most maximum likelihood analyses.

For Bayesian estimation of phylogeny, we employed the program PHASE 2.0 [52] due its inclusion of a great variety of models which encompass base-pairing in stems [53]. Testing each of these models is beyond to the scope of the present study. The aim here is to verify the impact of relaxing the character independence assumption among stem nucleotides on the topology recovered. Hence, the following models were tested using Bayes factors as criteria [54]: (a)
A uniform "4by4" nucleotide model, GTR +I +G, a choice made with the assistance of the jMODELTEST program [55]; (b) Distinct GTR +I + G models were employed for stems and loops; (c) GTR $+\mathrm{I}+\mathrm{G}$ model for loops and a 7A for stems. The 7A model is the most general reversible 7 -state model, i.e. one model the base-pair states A:U, U:A, G:C, C:G, G:U, and UG were assumed to be matches and all other base-pairs were lumped in a single mismatch MM state. The model includes 26 free parameters and allows base pair reversal asymmetry, an apparently biologically sound property of the model [56]; (d) GTR +I +G model was assigned to loops and a $16 \mathrm{~A}$ model to stems. A general time reversible 16 state model would include 134 free parameters, which reduces its utility to real data. In the $16 \mathrm{~A}$ model, it is simplified to include only 19 free parameters. There are three $\alpha_{i j}$ parameters for the six main states, modeling simple substitutions, double substitutions and double transversions; a single parameter for mutations to and from mismatch states and a parameter for single mutations between mismatch states.

Flat priors were used for all analyses. Four Markov chains were used in three runs of the same analysis starting from randomly built trees. At least eight million generations were run to ensure that sampling adequately explored the parameter space. The degree of convergence in tree topologies, clade posterior probabilities 
and parameter posterior probabilities across all analyses were analyzed in the program TRACER ver. 1.4.1 [57], which provides graphical plots and numeric reports of the estimated sample size (ESS). For this purpose Phase outputs were edited using Perl scripts designed by J.J. Gillespie, M.J., Yoder http://hymenoptera.tamu.edu/rna, slightly modified by the authors. Plots for the LnL of the stationary phase of each one of the models may be found in the additional file 3 .

\section{Analysis using parsimony as optimizing criterion}

Three different approaches were employed for analyzing data under the parsimony criterion. All employed the program POY 4.0 [58] since it also analyzes static alignments and morphological data using standard treesearching algorithms, yielding results equivalent to programs like NONA and TNT. For analysis including only static alignment and morphology the results were checked using TNT [59]. Analyses were run at the 32processor computer cluster held at Departamento de Zoologia da Universidade de São Paulo.

In the first, hereafter named 'traditional', analysis only the aligned nucleotides were included and gaps were scored as a fifth state. Heuristic searches were carried out using TNT employing 'New Technology search' (10000 random seeds, search including Ratchet and Tree-fusing, ran until the same strict consensus was hit ten times) and POY analysis (20 rounds of a POY script including the commands: build (320); perturb (iterations:10); swap (trees:1, annealing:(20, 2))).

In the second, a 'standard POY analysis' was performed employing direct optimization. Wheeler \& Hayashi [9] and Giribet et al. [10] employed this approach for inferring chelicerate phylogeny. Direct optimization (DO) allows skipping of the intervening step of multiple sequence alignment by searching simultaneously for the best tree under an optimization criterion (in this case parsimony) and the nucleotide homology [60].

Similar to other automated programs for multiple alignments the POY final score is a function of a cost regime chosen a priori. In a standard direct optimization inference, as many cost regimes as possible are employed in independent runs and the one which minimizes incongruence among data partitions (different genes, genes $\times$ morphology, different gene regions etc.) is chosen [61]. These runs are also used to explore the behavior of data across the parametric space and, according to Giribet [62], is a way of evaluating node stability (contra [63]).

The SSU rRNA unaligned sequences were spliced into 12 blocks using conserved regions as a reference and, along with the LSU fragment, analyzed under direct optimization (DO) as implemented in the POY 4.0 program. For the sensitivity analysis the following cost regimes were tried (gap extention: tranvertion: transition ratios): 111, 121, 112, 211, 221, 411, 412, 421.

Search rounds using a POY script included alternate SPR and TBR after building 320 initial Wagner trees (build (320); swap (trees:1, annealing:(20,2))) and was repeated at least 20 times. Results from each one of these costs regimes were evaluated using congruence as a criterion. This was achieved using an ILD metrics (Incongruence Length Difference, [64]). For ILD calculations data partitions considered were the SSU and LSU rRNA sequences:

$$
\begin{aligned}
& \mathrm{ILD}=\text { (combined length } \\
& -\Sigma \text { length from individual data sets }) / \text { (combined length) } .
\end{aligned}
$$

Jordal et al. [65] employed an interesting approach. They combined the secondary structure-based alignment to each of the RAA's in a POY analysis, analyzing each fragment in different data sets. This avoids violating positional homology where it may be inferred by secondary structure and explores the phylogenetic signal from regions where it is otherwise impossible.

A similar approach is employed in this study and compared with a standard DO analysis.

We have labeled this a 'constrained POY analysis'. For the RAAs, DO was employed with the same cost regimes employed in the standard analysis described above. For the pre-aligned regions, all transformations were equally weighted under static homology. We proceeded in this way because there is no objective justification for differential weighting in this case.

For the later analysis, the single strand RAA in the stems' tips were lumped with the REC. We proceeded in this way because the individual nucleotide homology cannot be accessed with confidence, due to possible exchange of nucleotides between REC and terminal loop RAA. The POY inputs for these analyses are presented in the additional file 4.

\section{Morphological and combined analysis}

Morphological character statements were largely derived from the primary literature, authoritative reviews or direct observations. They are summarized in additional file 5 and any discrepancies between our own interpretations and previous hypothesis are discussed there. The full data matrix includes 178 characters and is hereafter named matrix A and presented in the additional file 6 .

We were interested not only in knowing how combining the morphological matrix we gathered impacts the topology recovered by the combined analysis, but also in detecting any eventual limitations of direct optimization in maintaining the molecular characters' independence. For this purpose our results were compared with analysis combining the molecular data with a matrix produced applying Shultz's [22] character statements to the sampled taxa. 
This matrix - the most complete overview of arachnid morphological characters published thus far - is hereafter named matrix B - also presented in the additional file 6 .

The combined analysis using the matrices $\mathrm{A}$ and $\mathrm{B}$ repeated the three analyses described above for the molecular data. The cost regimes tested were the same as the molecular analysis described above and the criterion of cost regime selection was also congruence as measured by ILD metrics. For a given cost regime other than 111, morphology was weighted according to the ratio of the molecular tree length obtained in this cost regime and that obtained in 111. It was made for trying to keep the morphological contribution to the final result approximately constant.

Results for the constrained analysis combined with matrix A is the preferred hypothesis. For this, after completing the sensitivity analysis, we used all resulting trees from all parameters for tree fusing [66]; a technique designed for avoiding heuristic problems [67].

It is important to bear in mind that re-sampling measures of support in the DO context is not directly comparable to that in a static homology context, since the first sampled entities are sequence fragments and not individual nucleotides. Thus, for evaluating branch support, Bremer supports were considered more informative and were calculated for the constrained analysis combined with matrix A.

\section{Results}

\section{Data characteristics and rRNA secondary structures}

The SSU rRNA sequences in the 91 species in this study ranged from 1713-2154 nucleotides from helices 5 to 49; the longest sequences being observed in Tetranychoidea (Tenuipalpus hevae). The length variable regions are plotted against the secondary structure inferred for Rostrozetes ovulum (Acariformes, Oribatida, Fig. 2A) which is consistent with the general model for eukaryotes [40]. Nucleotides included in the aligned matrix are shaded in gray. Combined, they comprise 1581 positions, 747 being conserved, and among the remaining 813 variable positions 568 are parsimony informative.

When combined, all regions of ambiguous alignment (RAAs, RECs and RSCs) ranged from 171-610 nts. If Tetranychoidea are excluded we observe a range from 171-263. Despite their length, Tetranychoidea SSU rRNA molecules do not present major changes in the secondary structure as the length variations are related to the hyperextension of RECs. An exception is a putative new helix in the $\mathrm{V} 4$ region (Fig. $2 \mathrm{~B}$, depicted in red). This helix, which comprises 49-66 nts, should be considered exclusive to Tetranychoidea and hence is excluded from the analysis which considered the secondary structure information.
The LSU rRNA fragment ranged from 284-350 nts. The largest inside-order variation was obtained among spiders: 284 nts for the Pholcidae species and 349 for Atypoides riversi. The secondary structure inferred is consistent with that proposed for eukaryotes by Schnare et al. [45]. A notable secondary structure variation is the absence of the D3_1 helix in Pholcidae, Tetragnathidae, and all Acariformes. Although some Acariformes species possess potential base pairing in the corresponding region (see e.g. R. ovulum in Fig. 3A), they do not exhibit covariation for postulating a helix in this region for the order. This region includes 3-34 nts in Acariformes; five in the Pholcidae species; four in the Tetragnathidae species; and 17-50 nts in species which present a D3_1 helix.

The replacement of one secondary structure for another may be regarded as alternative states of a qualitative character. Thus a morphology-like character was added to the analysis, scored as 1 for taxa in which the D3_1 helix is absent and 0 for those in which it is present. Furthermore, individual nucleotides comprised in these different structures are not directly comparable and were set into different files when integrated into the POY constrained analysis.

Finally, when the D3_1 helix is taken in isolation, the covariation along the basal portion of the helix allows inference of the nucleotide homology for the blueshaded nts in Fig. 3B. Hence, the region was divided in three smaller sequences; one treated as pre-aligned and two under direct optimization.

The aligned data set derived from the LSU sequence contained 256 positions, of which 95 were conserved and 125 parsimony informative.

The combined $18 \mathrm{~S}$ rRNA plus $28 \mathrm{~S}$ rRNA pre-aligned data set has a mean base composition across the entire matrix as follows: $\mathrm{U}=23.1 ; \mathrm{C}=22.3 ; \mathrm{A}=26.4$; and $\mathrm{G}=$ 28.2. When only loops are taken into account the composition is $\mathrm{U}=22.7 ; \mathrm{C}=17.1 ; \mathrm{A}=38.3$; and $\mathrm{G}=21.9$, while for stems it is $\mathrm{U}=23.5 ; \mathrm{C}=26.6$; $\mathrm{A}=16.7$; and $\mathrm{G}$ $=33.2$. This compositional bias toward adenosines in loops was already observed in several datasets, and is explained by the high percentage of unpaired adenosine nucleotides in several structural motifs [68].

\section{Molecular analysis based on static molecular homology}

Bayesian analyses, considering the stems and loops as separate partitions, improved the $\mathrm{lnL}$ over the uniform GTR + I + G model (lnL harmonic means of -25881.12 and -26073.89 , respectively, $B_{10}=192.76$ ). But the Bayes factors clearly favor the mixed models that apply base pairing models for stems: GTR $+\mathrm{I}+\mathrm{G} \backslash 16 \mathrm{~A}$ and $\mathrm{GTR}+\mathrm{I}$ $+\mathrm{G} \backslash 7 \mathrm{~A}$, with an almost identical harmonic mean for $\operatorname{lnL}$ (-21674.70 and -21675.42). All Bayesisan analyses, however, presented similar topologies concerning 


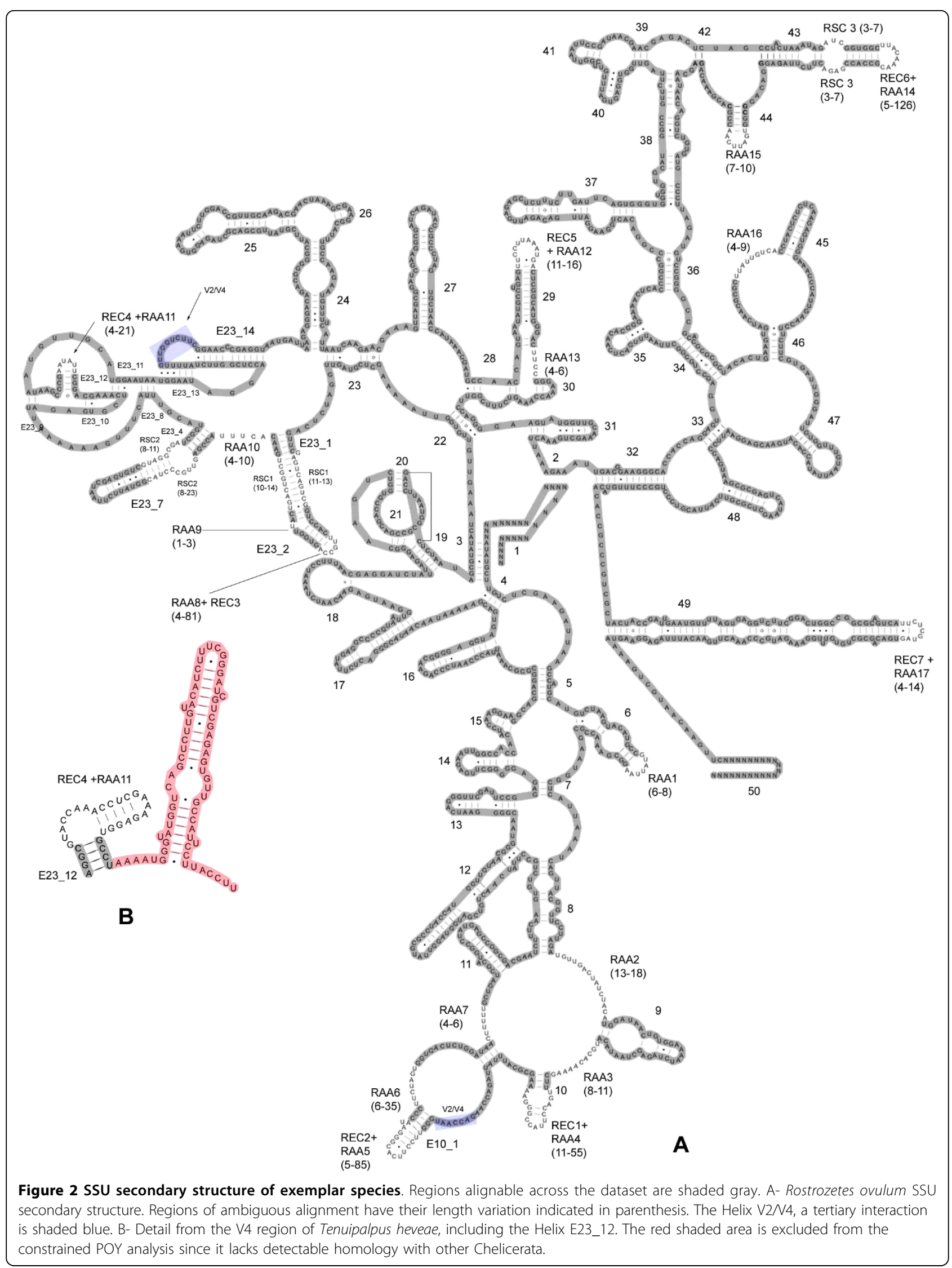




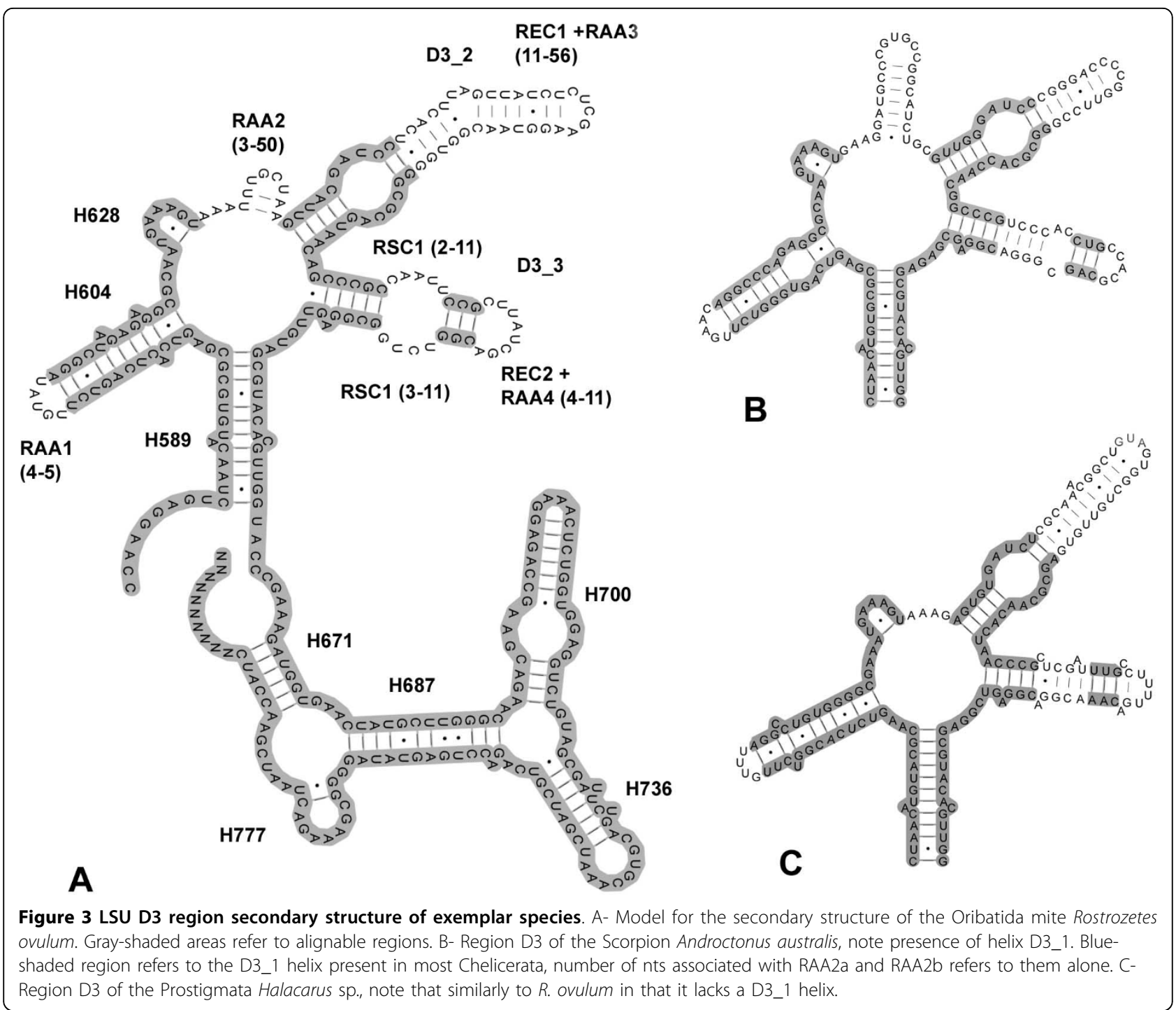

well-supported taxa. The phylogram presented here was recovered by the GTR +I +G\7A model (Fig. 4A).

The traditional parsimony based analysis, both employing POY and TNT reported 28 trees with 4982 steps $(C I=0,338 ; R I=0,600)$ when considering gaps as a fifth state. Jackknife supports were calculated as presented in Fig. 4B.

The Bayesian and parsimony analysis recovered almost all interordinal relationships with weak support (Jackknife $>50 \%$, Posterior Probabilities $>75 \%$ ) except for Uropygi (Thelyphonida + Schizomida) $(\mathrm{J} .=95 \%$, P. P = $100 \%)$ and Solifugae + Acariformes $(\mathrm{J} .=91 \%$, P. P. $=$ 100\%). All traditional orders except Acari, which resolve split into Acariformes and Parasitiformes, were recovered with high support; as well as Euchelicerata, but interestingly not Arachnida. Neither Labellata (Amblypygi + Araneae) nor Pedipalpi (Amblypygi + Uropygi) is recovered but (Uropygi + Araneae) is recovered with moderate support in the parsimony analysis $(\mathrm{J} .=53 \%)$ and high support in Bayesian analysis (P. P $=99 \%$ ).

Concerning Acariformes intraordinal relationships, it is noteworthy that Bayesian analysis recovers some traditionally held taxa with high support which are not recovered, or recovered with low support, in the parsimony analysis. This is the case for the families Bdellidae $(\mathrm{J} .=44 \%$, P. $\mathrm{P}=83 \%)$, Halacaridae (P. P $=99 \%)$, Astigmata + Oribatida Brachypylina (P. P $=100 \%)$, and Prostigmata (P. $\mathrm{P}=100 \%)$.

On other hand, parsimony analysis recovers with high support a Tetragnathidae + Pholcidae clade among spiders $(\mathrm{J} .=88 \%)$ while Bayesian analysis places Pholcidae basal among Araneomorpha with Tetragnathidae as sister to Nesticus; thus supporting Orbiculariae (P. P = $100 \%$ ) and Entelegynae (P. P $=100 \%)$. The Bayesian 


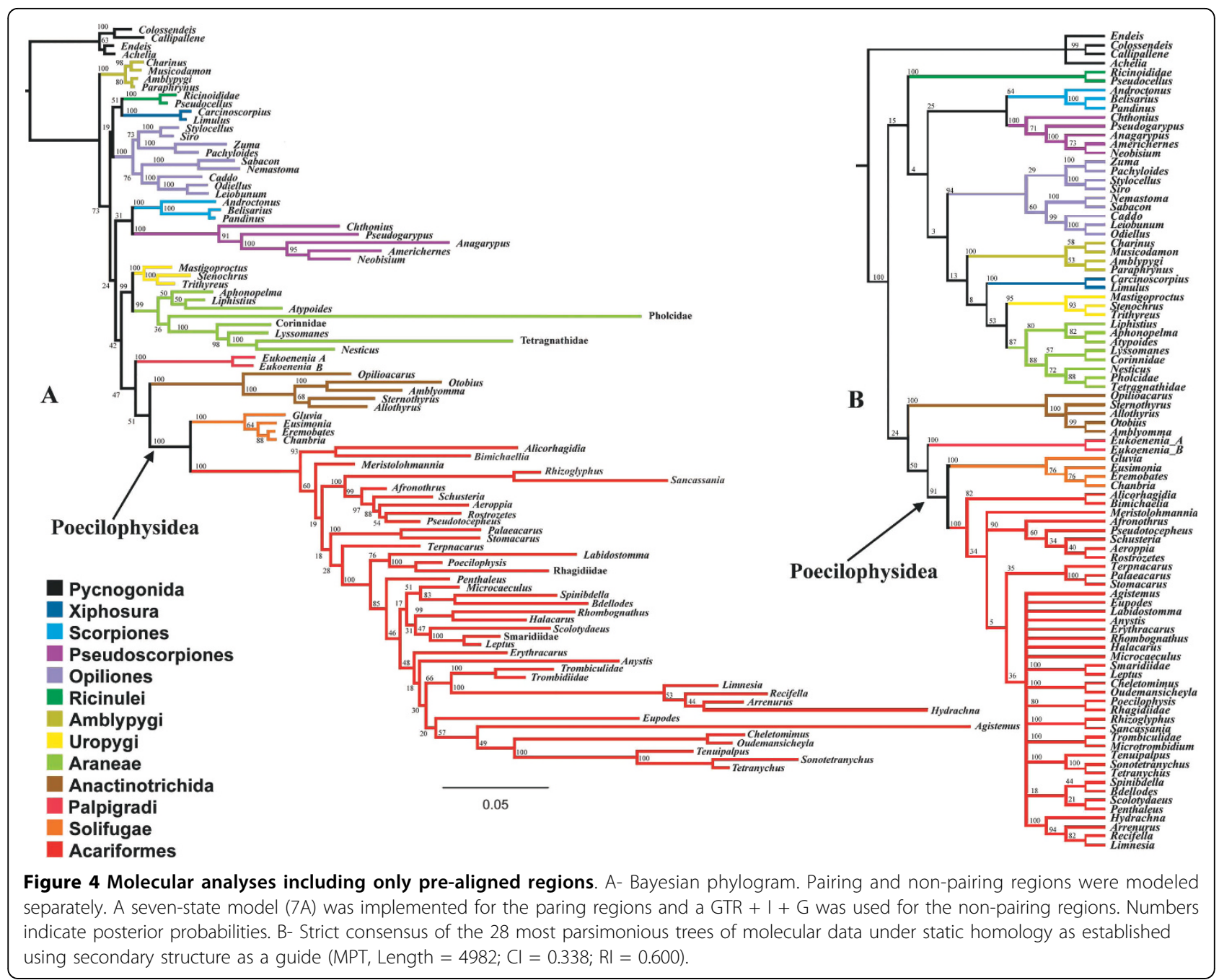

analysis estimated long branches leading to both Pholcidae and Tetragnathidae and their association in the parsimony analysis is regarded here as a long branch attraction artifact. Concerning spiders, however, Bayesian analyses oddly do not support Mygalomorpha monophyly.

\section{Morphological analyses}

As stated in the methods section, two different morphological data matrices were assembled for testing the impact of morphological data sets on the combined analysis. The trees recovered from the analysis of both matrix A and B are similar in supporting Amblypygi as sister group of Uropygi (Pedipalpi), Tetrapulmonata, and Arachnida (Figs. 5A and 6A, respectively).

Analysis of matrix A (characters recognised here) recovered neither Acaromorpha sensu Shultz nor Haplocnemata. Palpigradi was recovered in a basal position relative to a polytomy composed of (Tetrapulmonata + Ricinulei), Parasitiformes, Solifugae, and Acariformes
(Fig. 5A). Pseudoscorpiones resolve here as the sister group of Scorpiones instead of Solifugae, both associated with Opiliones.

Analysis of matrix B (Shultz's data) led to results similar to the original Shultz [22] analysis. It recovered Scorpiones as sister group of Opiliones, and a polytomy composed of Palpigradi, Tetrapulmonata, Acaromorpha sensu Shultz (Ricinulei, Acariformes and Parasitiformes), and Haplocnemata (Pseudoscorpiones + Solifugae) (Fig. 6A).

\section{Combined morphological and molecular analysis under static homology}

In the combined analysis under static homology (Figs. $5 \mathrm{~B}, 6 \mathrm{~B})$, Solifugae was recovered as the sister group of Acariformes mites irrespective of the morphological matrix employed. Tetrapulmonata was also recovered in both analyses. Neither matrix A nor B led to a well supported position for Ricinulei plus Parasitiformes mites, but the combined analysis employing matrix 


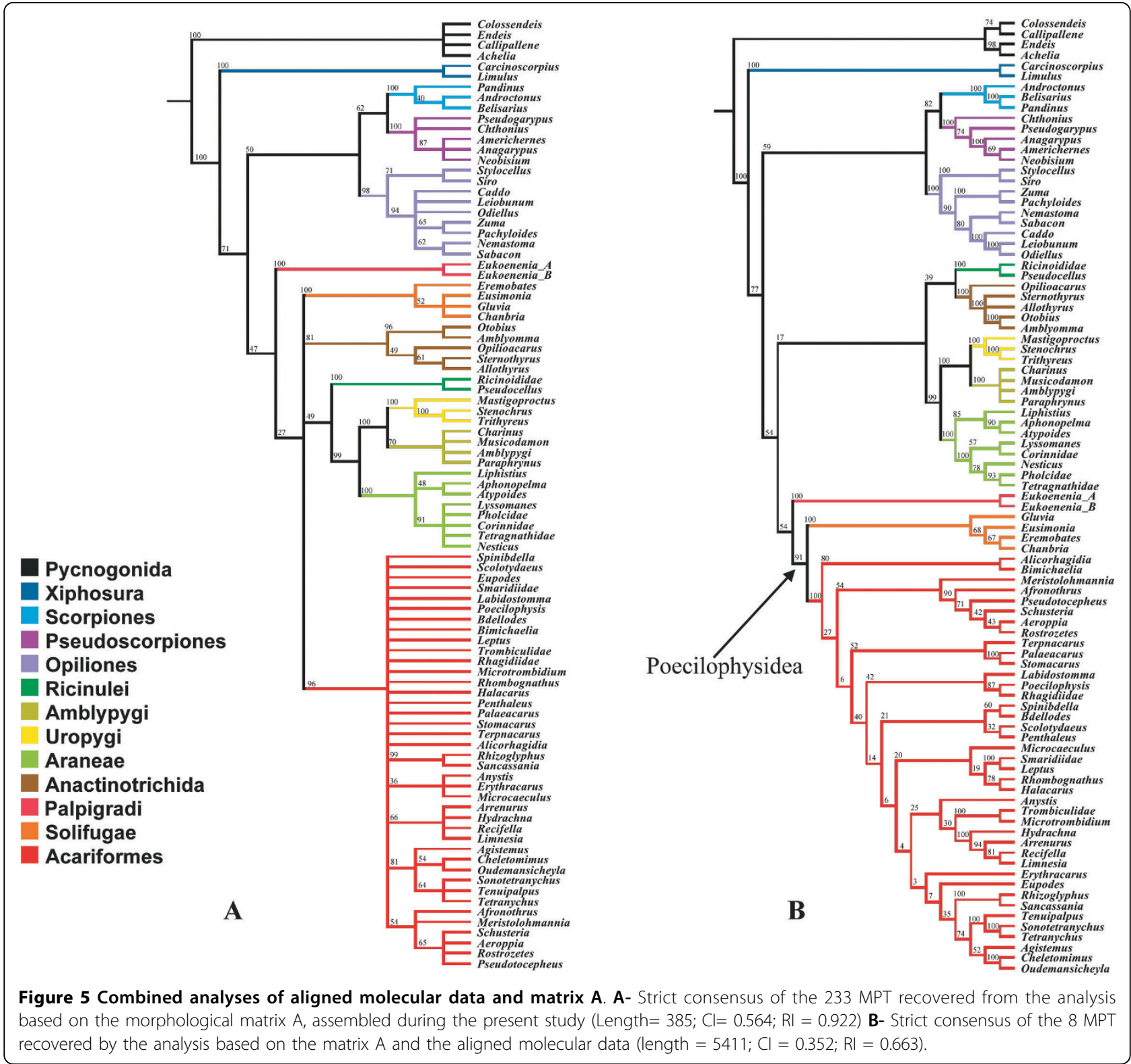

A recovered a taxon composed of (Opiliones (Pseudoscorpines Scorpiones) $(\mathrm{J} .=59 \%)$. These three orders appear in the topology recovered using matrix $B$ in a polytomy. Palpigradi is recovered as sister group of (Solifugae Acariformes) in both analyses, with Jackknife supports of $54 \%$ and $37 \%$ respectively.

\section{Molecular analysis integrating Regions of Ambiguous Alignment}

The first noteworthy difference between the standard and secondary structure constrained POY analysis was the computational time required for similar searching strategies, with the former taking approximately 8.7 times longer than the later using the same number of processors. The standard POY analysis recovered a single more parsimonious tree with a length of 9998 steps, $\mathrm{CI}=0.434, \mathrm{RI}=0.676$ (Fig. $7 \mathrm{~A}$ ). The cost regime to minimize incongruence was that with all changes equally weighted (ILD metrics summarized in Additional file 7). The constrained analysis yielded a single MPT, 10095 steps long, with $\mathrm{CI}=0.412, \mathrm{RI}=0.638$, incongruence leading to the choice of the same 111 cost regime (Fig. 7B).

The optimal topologies are similar with respect to most interordinal relationships. They both present the clades (Palpigradi (Solifugae Acariformes)), (Scorpions Pseudoscorpions), and (Ricinulei (Amblypygi (Araneae (Thelyphonida Schizomida)))). 


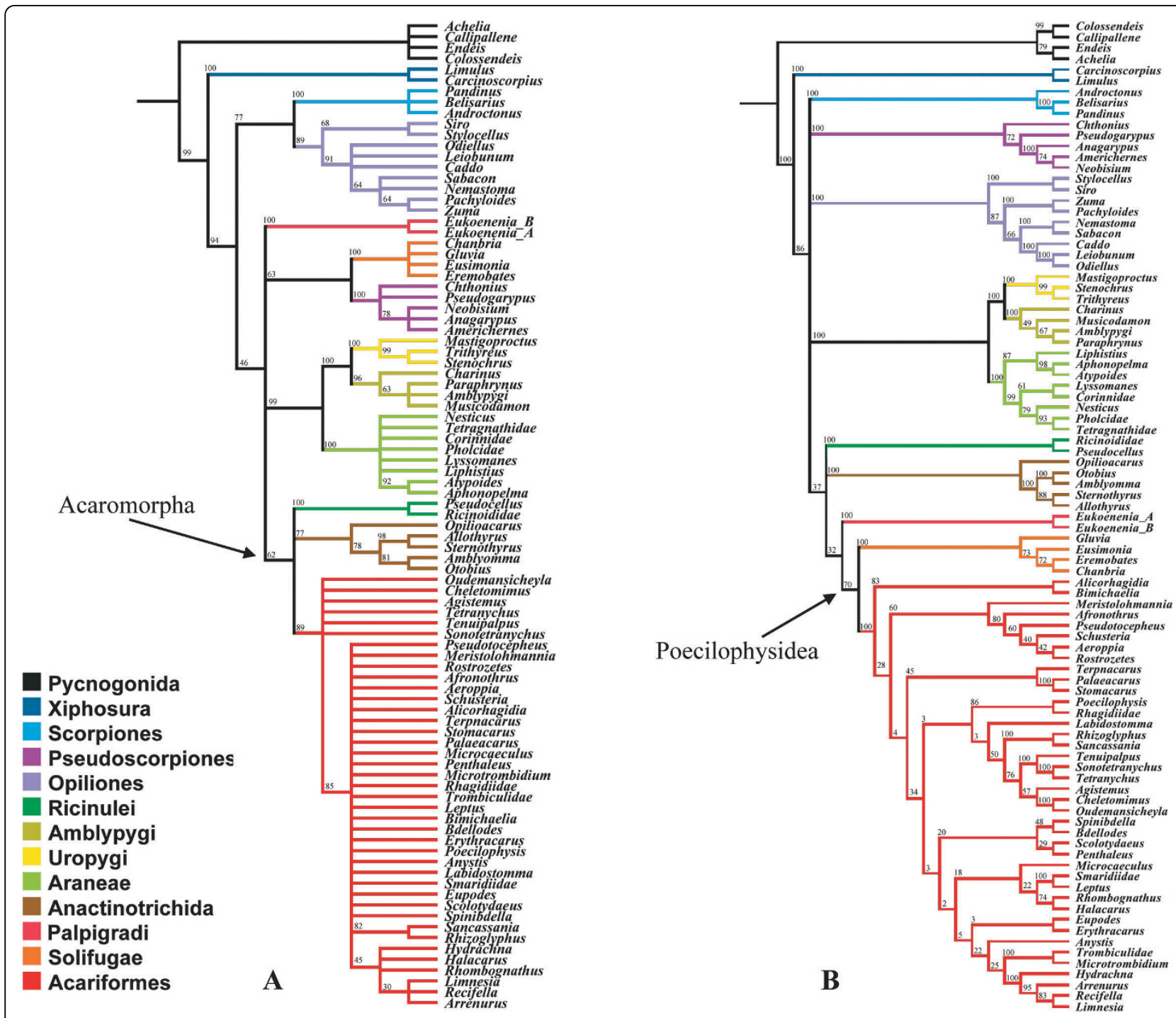

Figure 6 Combined analyses of aligned molecular data and matrix A. A- Strict consensus of the 1482 MPT recovered from the analysis based on the morphological matrix obtained from Shultz's (2007) study (Length $=420 ; \mathrm{Cl}=0.548 ; \mathrm{Rl}=0.913$ ) B- Strict consensus of the 4 MPT recovered by the analysis based on the morphological matrix $B$ and the aligned molecular data (length $=5447 ; \mathrm{Cl}=0.352 ; \mathrm{Rl}=0.661$ ).

All traditional orders, except Acari, are recovered in both analyses at the optimal cost regime. However, only the cost regimes 111, 112, 121, and 221 recovered Araneae in the standard analysis. The order is not supported under the cost regime 412 in the constrained analysis only. Parasitiformes is oddly recovered as a basal offshoot in both analyses.

\section{Unconstrained combined analyses}

The unconstrained combined analyses are remarkable for presenting ILD values almost identical for the costs regimes 111 and 121 . The former cost regime was chosen arbitrarily for presenting the topologies in Figs. 8A and 9A. Results differ between the cost regimes no less because the later presents Arachnida as a monophyletic group. The ILD metrics for all analyses are summarized in Additional file 7.

Combined unconstrained analyses of the molecular data and matrix A yielded a single MPT with 10451 steps, $\mathrm{CI}=0.432, \mathrm{RI}=0.694$ (Fig. 8A). When combined with matrix $\mathrm{B}$, the unconstrained analysis recovered a single MPT, with 10491 steps, $\mathrm{CI}=0.434$; and $\mathrm{RI}=$ 0.685 (Fig. 9A).

The former yielded Solifugae as sister group of Acariformes. The latter did not recover the (Palpigradi (Solifugae Acariformes)) clade found in the purely molecular analyses and remaining combined analyses. Instead, Acari was recovered as monophyletic and associated 


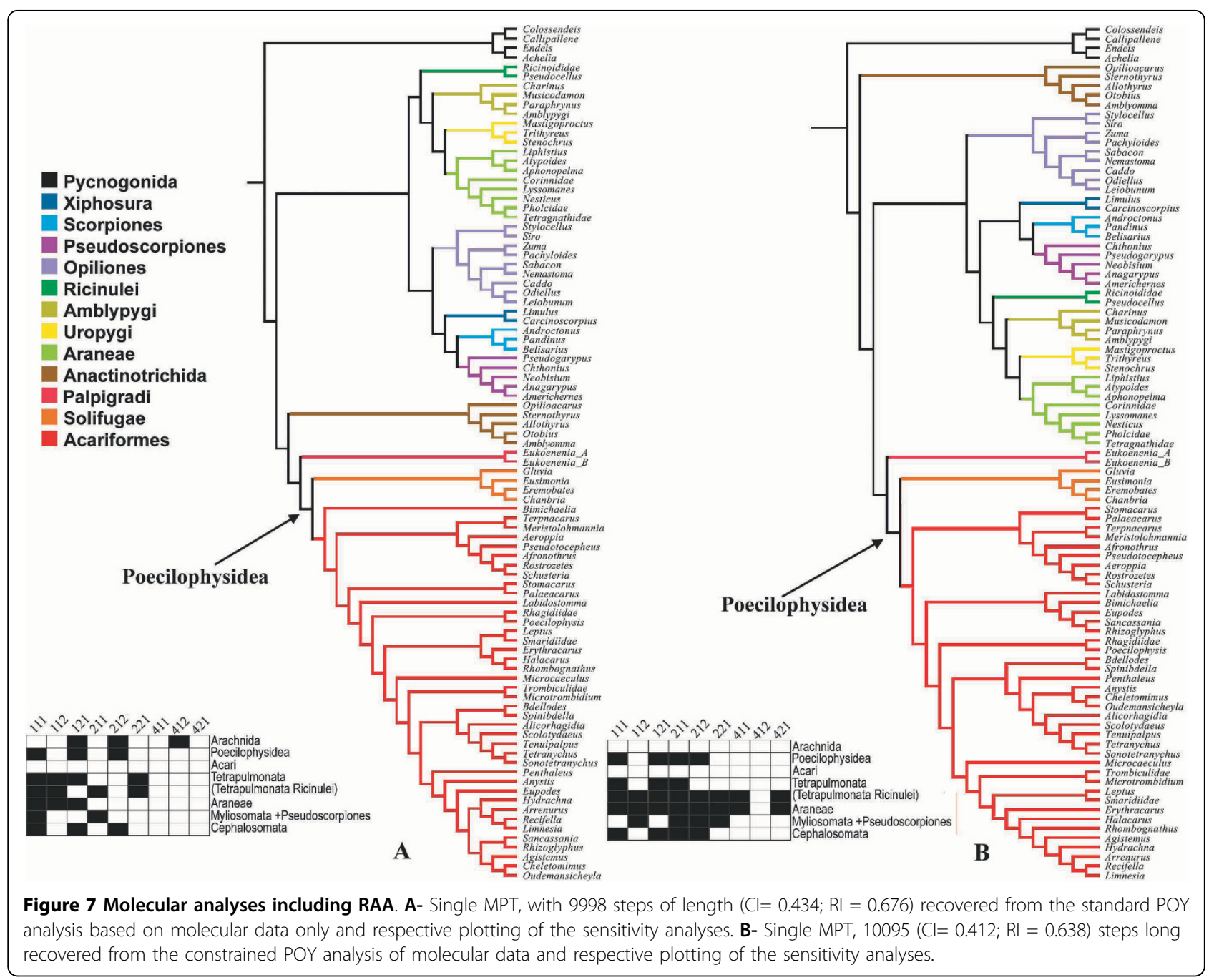

with Solifugae. Furthermore, Palpigradi was recovered as basal, i.e. as sister group of all other Euchelicerata orders.

\section{Constrained combined analyses}

The ILD metrics unambiguously point to the cost regime 111 as optimal for both matrices $\mathrm{A}$ and $\mathrm{B}$. While the unconstrained analyses yielded considerable change in optimal topology with respect to the morphological matrix with which it was combined, the secondary structure constrained analyses resulted in the same interordinal scheme of relationships; albeit with different frequencies along the sensitivity analyses. The analysis combined with Shultz's matrix B resulted in a single MPT with 10587 steps in length $(\mathrm{CI}=0.411$; $\mathrm{RI}=$ 0.659 , Fig. $8 \mathrm{~B}$ ), the analysis combined with matrix A yielded to a single tree with 10548 steps in length $(\mathrm{CI}=$ 0.412; $\mathrm{RI}=0.666$; Fig. 9B). The resulting topology is discussed in further detail below and the respective Bremer support values are displayed for its branches in Fig. 9B.

\section{Discussion}

\section{Methodological remarks}

One of the most exciting aspects of phylogenetic studies is that methodological concerns should, more often than not, be addressed simultaneously with the phylogenetic inference. Except for bizarre exceptions, such as short term viral evolution, true phylogenies are unknown. The alternative employment of simulated data or well-supported phylogenies must not preclude the researcher thinking about their own practice.

Shultz [22] brought our attention to the fact that "There is a tendency to portray arachnid ordinal phylogeny as more poorly resolved and contentious than is actually the case". If only the morphological and combined analyses are taken in consideration, this is certainly the case, although the results obtained by purely molecular analyses depart considerably from this convergence.

A possible explanation for this apparent contradiction is the way that molecular homology was established in 


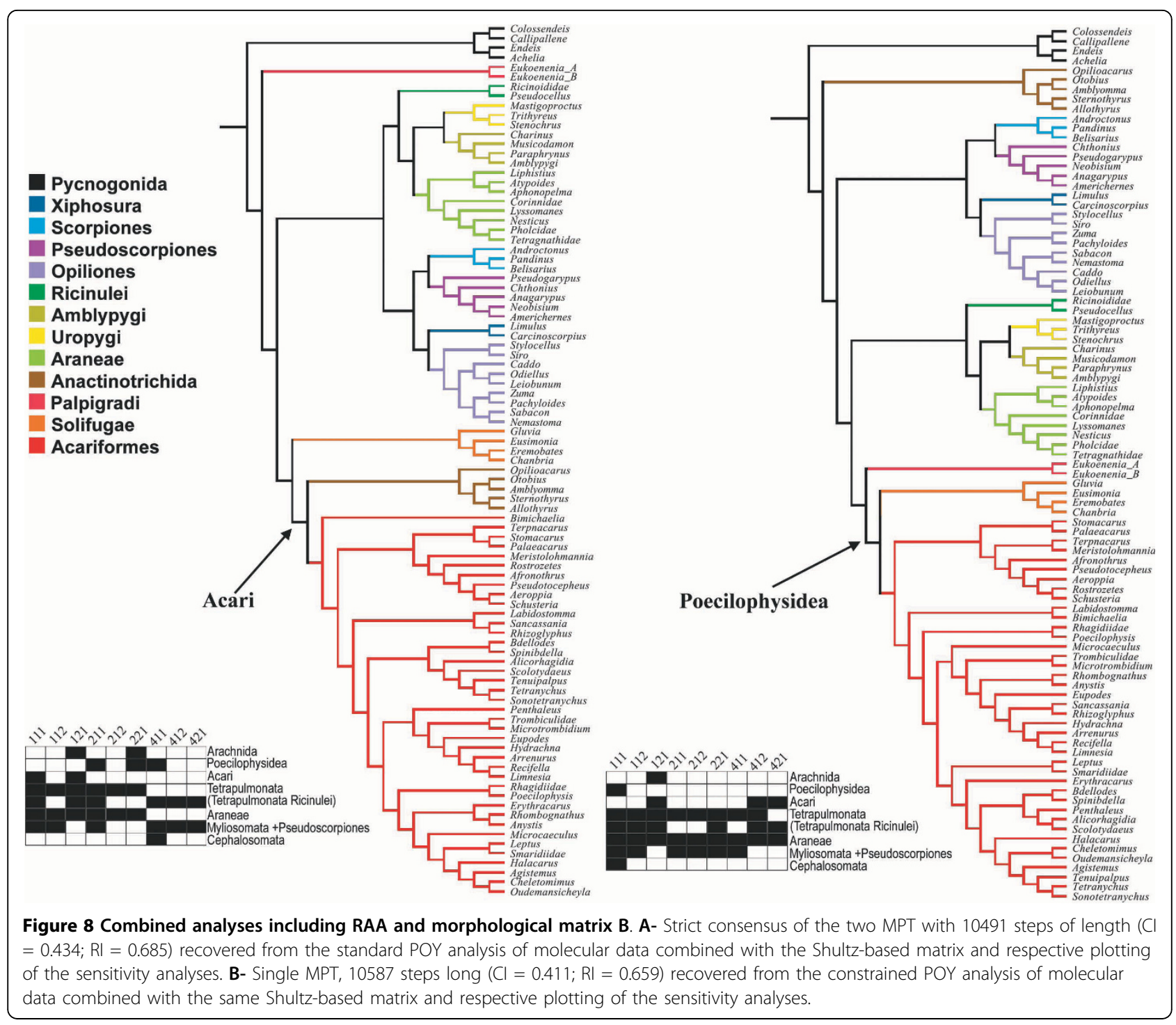

those combined analyses that preceded us. Direct optimization was already criticized on the grounds of its possible inaccuracy in recovering nucleotide homology when compared with more traditional algorithms such as Clustal W [69] (contra [70]) and secondary structure alignment [71]. Our combined analyses results, however, may be better explained by another drawback, the lack of independence among data partition, which we here discuss further.

As in other comparative sciences, systematics is based on the concept of homology. The formulation of a hypothesis of character homology is a two step process: (a) from observations and knowledge external to the analysis researchers propose characters and their states, after which (b) several independently formulated characters are assembled into a matrix and subjected to cladistic analysis. Only after the phylogenetic analysis is it possible to distinguish between similarity due to convergence and shared ancestry, by using character conflict or conformation to the optimal topology [72]. This double nature of homology is further discussed by Assis \& Brigandt [73].

In molecular systematics, primary homology assessment is accomplished by multiple sequence alignment, which is crucial for ribosomal genes that may vary in length by hundreds of nucleotides. Multiple alignments have been considered a computational rather than a biological issue and much more effort has been employed in improving algorithms for matching individual nucleotides under a similarity criteria than to address what evidence must be pursued for aligning nucleotides that share evolutionary descent (see Morrison [74] for a revision).

Length variation yields considerable phylogenetic signal [75], but also produces uncertainty in nucleotide 


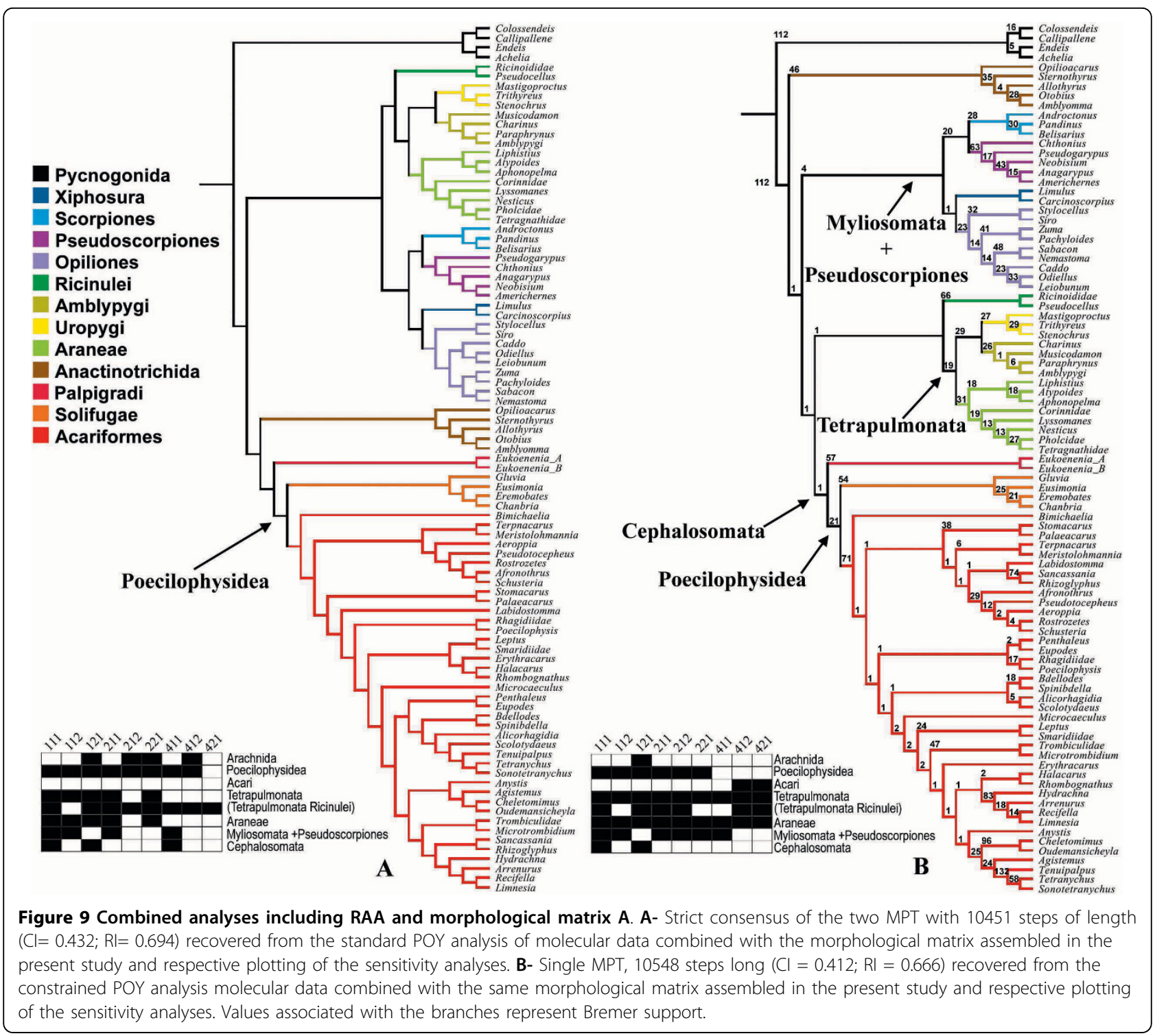

homology. Usually, regions of ambiguous alignment (RAA) are detected by alignment inspection and then discarded. Along with these discarded regions, any phylogenetic signal they might have contained is obviously lost. To avoid such 'wastage' several methods were proposed for incorporating RAA into the phylogenetic analysis [76].

Direct optimization circumvents it by inferring phylogeny and homology simultaneously, in a 'one step' approach. Wheeler \& Giribet [77] made clear their judgment on multiple alignments and considered it a nonscientific procedure. In their opinion molecular data must be analyzed as they are obtained from sequencing. In fact, proponents of POY consider multiple alignments to be more than useless; even deleterious to the analysis:
"In the same way that each cladogram has a (potentially) unique set of optimal character origins, each cladogram may have a unique set of optimal correspondences among observed features. Unless these correspondences are unrestricted and allowed to be optimized together with transformations, biased and conditional results may be obtained. Such bias may come from assumptions of the investigator and his or her notions of appropriateness of comparison, and conditioned on the hypotheses most in agreement with preconceived correspondences of 'primary' homology" (Wheeler et al.[[78], p. 11]).

Wheeler and colleagues advocate instead an approach to systematics classified as 'instrumentalist' by Rieppel 
[79], which embraces a specific stand point on the nature of evidence in phylogenetic inference. For these authors, evidence must enter directly into the analysis without being filtered by the (ever misleading?) researcher subjectivity, or constrained by considerations external to the phylogenetic analysis itself.

The reasoning elaborated by Simmons [80] led us to reject this perspective and is especially relevant for discussions concerning Shultz's [22] perception of convergence of results and the analyses presented here. Simmons [80] argued that the primary homology assessment step is an insurmountable requisite for phylogenetic analyses because it is a guarantee for maintaining character independence.

POY uses parsimony for optimizing nucleotide homology and congruence for parametric regime choice. Both parsimony and congruence require that characters are independent within and among data sets. If a character state lies on the state of another character, a single evolutionary event will be over-weighted. If character states in a data set lie on the character states in another dataset it is likely that the combined analysis will be biased toward a higher congruence among these datasets.

Character dependence may be the product of a shared causal mechanism, like sharing the same selective pressures. However, Simmons [80] argued that when combining unaligned sequence with static homology data (i.e. pre-aligned sequences or morphology) using POY, the final result will be biased toward the signal provided by the data under static homology. The cause of dependence in this case is not related to the underlying biological nature of the character, but rather by the way direct optimization works when establishing character homology in its 'one step' approach to phylogenies. The core of his criticisms on direct optimization is that such influence is sufficient to blur the phylogenetic signal of the unaligned molecular data. He argued that while optimizing tree length, potential conflict among molecules being analyzed under DO and characters analyzed under static homology may be erased by the algorithm moving unaligned nucleotides around. Rieppel [79] presented similar arguments and referred it as "the fluidity of character statements".

Usually, morphological data has a limited effect when combined with molecular data (see e.g. [81], for its impact on resolution and support). Morphological influence is arguably limited by the relatively small number of characters. However, during a standard POY analysis morphological data also contributes to the final topology by: (a) its effect on establishing the molecular homology under a given cost regime and (b) on the choice of the cost regimes, since this decision is taken on grounds of minimizing incongruence.

This suggests that lack of independence could explain the disparity between the position and monophyly of mites when combined analysis results are compared with exclusively molecular analysis, as per Wheeler \& Hayashi [9] and, mainly due to their improved sampling effort, in Giribet et al [10] and in our own analysis employing unconstrained direct optimization. It is exemplified in Fig. 10, where implied POY alignments correspondent to the trees recovered in the analyses combined with matrix A and B are compared, showing that molecular homology statements are diverse between the two analyses.

Although phylogenetic inference cannot be ascribed to a falsification context [82] (for an alternative standpoint see [83]), researchers are interested in at least verifying how plausible current hypotheses of relationships are. The 'epistemological interdependence' created by direct optimization makes this 'test' less rigorous and may preclude the discovery of potential homoplasy. For example, convergence of the gnathosoma between Acariformes and Parasitiformes is recovered in the constrained analyses of the present study, but not in the unconstrained one applying the Shultz [22] based morphological matrix.

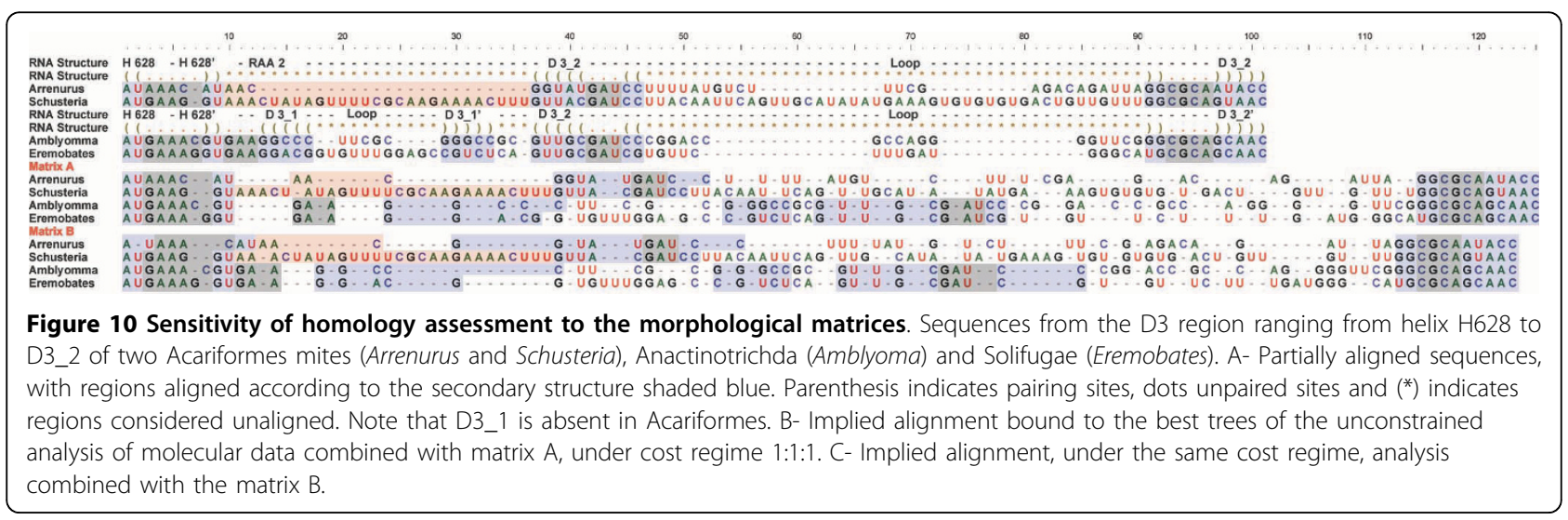


POY may share drawbacks with other automated multiple alignment programs. Hickson et al. [84] showed that any multiple alignment method which works at the individual nucleotide level is incapable of recovering homology relationships inferred from secondary structures in rRNA sequences, and this is clear in Fig. 10. The results of the present study have reinforced the potential of secondary structures to help formulate more accurate hypothesis of homology. This is indicated by the similar values of incongruence in the constrained analysis, a surprising result since POY seeks to minimize incongruence. Two clear examples of how secondary structure may be employed for data partition may explain this. Other interesting examples of how use secondary structure information in an analysis may be found in Swain \& Taylor [85].

In the first example, an extra helix, absent in all other Chelicerata could be determined in the Tetranychoidea species (Fig. 2B). The emergence of these structures has been documented ever since initial studies on secondary structures of ribosomal genes were carried out, e.g. [86]. The nucleotides contained in this new structure are arguably non-homologous to any others found among the remaining species, yet they are tentatively aligned automatically with nucleotides in other sequences using any of the cost based alignment algorithms, including POY.

In the second example, with more fundamental consequences for the present analyses, there are length convergences among some taxa. In Tetragnathidae and Pholcidae (both spiders), and Acariformes mites, which have convergently lost the D3_1 helix in the LSU fragment studied. We must also consider Atypoides riversi and Ricinulei which have large insertions in different, but contiguous, helixes (the LSU D3_2 and D3_3). These length convergences are easily amenable to homology establishment using secondary structure as a guide. In the spider-acariform case, the presence/ absence of the D3_1 helix is considered to be alternative states of a same character. In the second case, Atypoides and Ricinulei had their insertions set in different files. Otherwise, this situation led to spiders being recovered in just four cost regimes $(111,112,121,221)$, and oddly (Pholcidae, Tetragnathidae, Acariformes) in 411, 412, and 421 and (Atypoides Ricinulei) in 211 and 212.

Integrating the regions of ambiguous alignment ambiguous relative to the criteria adopted here for homology establishment - brings to the present analyses phylogenetic information which both supported Tetrapulmonata and placed Ricinulei as it sister group; two clades which have been suggested based on other lines of evidence (see below). It leads us to support the inclusion of these regions into phylogenetic analysis as argued by Giribet \& Wheeler [75], but with a note of caution when interpreting the results.

Any alignment is an inference, since gaps are not observed from sequencing results. Therefore, alignment includes a variable degree of uncertainty. In a standard analysis, where only regions regarded as unambiguously aligned are considered, this uncertainty is comfortably ignored by those who perform the analyses.

It is harder to do so considering the regions of ambiguous alignment. POY provides point estimation on the optimal alignment for these regions given a cost regime, but is uninformative on the impact of homology inference uncertainty on node support.

Furthermore, parameter choice is made among a limited set of cost regimes applied uniformly to the sequence and not estimated by the sequences properties. Redelings \& Suchard [87] proposed an algorithm for simultaneously estimating alignment and phylogeny, taking into account alignment uncertainty that circumvents this problem in a Bayesian frame. It is expected that such developments will allow further integration of RAA's phylogenetic information while at the same time considering the uncertainty in support estimation. Currently, however, the implementation of this method is practical only for smaller data sets.

Given the considerations above, the hypothesis that combines (a) a better knowledge of rRNA properties when establishing homology, (b) keeps the among-partition independence and (c) encompasses the information from the RAAs, is that recovered under the constrained analysis combined with matrix A (Fig. 9B). This hypothesis will be the basis for the following discussion.

\section{Phylogenetic position of Acariformes}

Acaromorpha sensu Shultz is supported neither by the morphological nor the molecular data presented here. In fact, both converge in placing Ricinulei as the sister group of Tetrapulmonata (i.e. spiders and their closest relatives), although with low Bremer support in the final analysis (Fig. 9B). Among the putative synapormorphies for (Ricinulei + Tetrapulmonata) we have the presence of a tritosternum, a feature also shared by several Parasitiformes mites (Ch. 12), a cheliceral apotele articulated dorsally (Ch. 28), loss of the proximal segment of the chelicerae, convergent with Acariformes mites, Solifugae and Pseudoscorpiones (Ch. 27), coiled sperm cells, shared with Pseudoscorpiones (Ch.162) and the presence of a machete of microtubules associated with the spermatid nucleus (Ch. 167). The association of Ricinulei with Tetrapulmonata is further supported by fossil data. Ricinuleids share several putative apomorphies with Trigonotarbida; a whereby (Trigonotarbida + Tetrapulmonata) together form the Pantetrapulmonata 
sensu Shultz [22]. As in the ground plan of Tetrapulmonata, trigonotarbids also have two pairs of book lungs in opsithosomal segments 2 and 3 respectively [88], as well as the typical tetrapulmonate 'clasp-knife' chelicerae. Explicit morphological characters supporting (Ricinulei + Trigonotarbida) include palpal chelae where the apotele opposes the tarsus (Ch. 41), presence of a locking mechanism between the prosoma and opisthosoma (Ch. 68), longitudinally divided opisthosomal sclerites (Ch. 69), and the presence of a diplosegment formed by the fusion of opisthosomal tergites 2 and 3 (Ch. 70) [18,19].

As discussed above, a monophyletic Acari could not be recovered in those cost regimes that minimized incongruence, except when combining the unconstrained data with matrix B. The position of Parasitiformes could not be further addressed here. In fact, we should regard this as a 'wild card' group. The basal position recovered from the present data is arguably an artifact and has no morphological support. An alternative hypothesis would be a sister group relationship between Acariformes and Ricinulei. This is the so-called Cryptognomae hypothesis, introduced by Hammen [13], with their putative sister group in his scheme being Trigonotarbida. Another possibility would be to treat anactinotrichid mites as a basal offshoot from the lineage leading to the Tetrapulmonata + Ricinulei group. The latter model would receive support from the presence of a tritosternum (Ch. 12) and the way coxal glands fluids reach the pre-oral chamber (Ch. 115). Finally, numerous molecular analysis have recovered Parasitiformes as the sister group of Pseudoscorpiones [10,11,23,24]. Characters such as the fusion of the labrum to the epistome, and a ventrally placed cheliceral apotele support this hypothesis (Ch. 13, 28), although neither of these traits are exclusive to them. It is noteworthy that all these mentioned analyses have not included basal Pseudoscorpiones, restricting themselves to members of the more derived Iocheirata.

\section{Solifuges and acariform mites}

The most significant result from the present combined study is a strong signal for a sister group relationship between Solifugae and Acariformes. Interestingly, the same result was obtained in the recent molecular tree of Dabert et al. [24] with similarly high support values; albeit using a slightly different set of genes (specifically we used D3 LSU rather than COI).

Dabert et al. [24] further discussed morphological support for this clade, mentioning similarities in the position of the tracheal openings of solifuges and at least the prostigmatid mites, or the potentially homologous lateral organs of Solifugae and the Claparède organ of Acariformes. From our character set we recognize the following putative apomorphies: a narrowing of the sternal region, the fusion of the labrum to the epistome, and a ventrally placed cheliceral apotele $(\mathrm{Ch} .7,13,28)$. Some of these character states are recovered as convergent with, respectively, Pseudoscorpiones (Ch 7), and/or Pseudoscorpiones and Parasitiformes mites (Ch. 13, 28). Exclusive to Solifugae and Acariformes are the putative synapomorphies of loss of the nuclear envelope during spermiogeneis (Ch.158, although a somewhat similar condition may occur in some Xiphosura), and the presence of a specific structure of the testis (Ch. 168).

This apomorphic histology of the testis is the most striking feature uniting solifuges and acariform mites $[20,89]$. This feature was overlooked by the Shultz [22] study, in which he accused (p. 236) Alberti \& Peretti, and other workers, of trying to "support specific (target) clades". Despite such criticisms it is interesting to note that the explicit character of testis morphology which Alberti \& Peretti formally proposed in support of solifuges and acariform mites was conspicuously absent from Shultz's own morphological matrix. One can also target clades by excluding data a priori.

Considering the testis character in detail, in Parasitiformes mites, for example, spermatogenesis progresses in a roughly anterior-posterior direction along the testis, and spermatogonia are observed in adults. Secretory cells are lacking in the testis. In Acariformes, by contrast, no spermatogonia are observed in adults and meiosis putatively occurs only in juveniles. Furthermore, the testes have a dorso-ventral orientation with a dorsal germinative region delivering sperm cells to the lumen, apparently by germinative epithelia fragmentation, while the ventral secretory specialized epithelia deliver a sperm-accompanying secretion through a more or less developed brush border. This dorso-ventral orientation is also clear in spermatid development with mature sperm cells restricted to the ventral portion of the germinative region. Exactly the same condition is observed in Solifugae, except that here only mature sperm cells are documented in adults.

As noted by Dabert et al. [24], a possible relationship between solifuges and acariform mites also has historical precedence [90]. Cambridge [91] described a rhagidiid mite as a new arachnid order which he named Poecilophysidea; considering it a mite-like animal, but with solifuge-like characters. Banks [[92], pp. 21-22] later claimed with reference to Rhagidia: "Its structure is in many ways very similar to that of certain solpugida and suggested to Thorell its generic name, which is a diminutive of Rhax, a genus of Solpugida. It is probable that, it is the most primitive of all existing mites, and points to a close relationship of the Acarina to the Solpugida." Rhagidiids do look, at least superficially, rather like tiny solifuges. While most cladistic work on mites including the present study - has not recovered 
Rhagidiidae in a particularly basal position among the Acariformes, Dabert et al. [24] mentioned that this family was recovered either basal within the Eupodides clade or even basal among Trombidiformes; at least under some parameters of analysis. Given the new phylogenetic hypothesis linking solifuges and mites, further tests of the position of rhagidiids would be welcome.

Alternatively, Grandjean [93,94] drew comparisons between solifuges and another group of acarifom mites; the probably basal oribatid lineage Palaeacariformes. Grandjean highlighted similarities such as a dorsal sclerite (or propeltidium) associated with the first four pairs of appendages (our Ch. 1), the projecting mouthparts (Ch 13) and the Claparède/lateral organ (but see our Ch 175). As noted by Dunlop \& Alberti [6], high-quality morphological studies incorporating both mite and nonmite arachnids are largely lacking and we hope that the results of the present analysis will encourage further comparative research of this nature. In this study, we choose to name the putative clade encompassing Solifugae and Acariformes as Poecilophysidea, in recognition of Cambridge's the early acknowledgement of the similarity between the two orders.

\section{The palpigrade problem}

Palpigradi is one of the least known of the extant arachnid orders. Certain characters, such as the morphology of the endosternite, have led some authors to consider them as basal Arachnida [95]. Alternatively, palpigrades have previously been considered closely related to Acariformes mites [23,96] or Tetrapulmonata [16]; while Shultz [22] recovered them unresolved with respect to his other major arachnid lineages. The position of Palpigradi which is most stable, although with weak support, in the present analysis is as sister group of the Solifugae + Acariformes clade: a hypothesis we will name hereafter as "Cephalosomata".

The name Cephalosomata highlights the absence of a unitary carapace covering the first six appendage-bearing segments. Instead, as in Pycnogonida and Schizomida the group Palpigradi, Solifugae and Acariformes (due its sejugal furrow) present the four anterior appendage-bearing segments covered by a shield variously named the cephalosoma (which technically refers to the body region) or the propetildium (the dorsal shield itself) [97].

Significantly, Cephalosomata is only recovered when molecular data is brought into the analyses, but shares, besides the cephalosoma/propetidium (Ch. 1), the absence of a sperm cell flagellum (Ch. 161, convergently lost in Parasitiformes and Phalangida harvestmen and scored based on Prokoenenia, since the genera Eukoenenia has not been studied with respect to this feature); presence of a secretory region on the coxal glands
(Ch. 115) and the putative number of body segments (Ch. 66); both character states modified or lost in Acariformes. These characters are admittedly highly homoplastic and possibly under-studied, yielding only weak morphological support for this clade. The constrained analysis combined with matrix A also recovered Cephalosomata, although with a low Bremer support (Fig. 9B).

Despite this, we suggest that some aspects of Cephalosomata morphology may yield novel data for the group. Solifugae is unique among Arachnida for displaying the most complete set of embryological opisthosomal appendage buds, comprising transitory appendages from the first to the tenth opisthosomal segments [98]. Most of them degenerate quickly, but tracheal stigmata develop behind the $3^{\text {rd }}$ to $5^{\text {th }}$ segments. These same segments develop the putative respiratory lung sacs (or 'ventral sacs') in some Palpigradi, but since embryology is largely unknown for this group it remains equivocal as to whether these sacs in palpigrades are appendage derivatives too. 'Ventral sacs' are often treated as homologous to similar structures seen in Amblypygi [99], but they were regarded by Hammen [96] as homologous to the genital acetabula in Acariformes due their similar post-embryonic development.

The appendicular nature of the genital acetabula is not demonstrable from traditional embryological observations of Acariformes, since appendage buds in the appropriate position have never been recorded for this group. Yet the acetabula share the same fine structure and function as the epimeral pores or Claparède organs $[100,101]$, which are demonstrably exopod derivatives among the mites. In summary, Palpigradi 'lung sacs', Solifugae spiracles and Acariformes genital acetabula may be vestigial expressions of the same appendages on the same body segments. Moreover, we could speculate that the trilobated genital opening in both Palpigradi and Acariformes are homologous structures; as did Hammen [96].

\section{Arachnida and future prospects}

Finally, molecular data do not support a monophyletic Arachnida. In the optimal hypothesis, Xiphosura are recovered in a group including Scorpiones, Pseudoscorpiones and Opiliones. We should note that the last three orders are recovered together mainly thanks to muscular appendicular characters [15] in our morphological analysis (Fig. 5A). This clade recalls Dromopoda, sensu Shultz [16], but here excluding Solifugae and including Xiphosura, or Hammen's 'Myliosomata' (here including Pseudoscorpiones); see Hammen [14] for a discussion of this group defined on 'coxisternal' feeding.

Challenges to arachnid monophyly have usually faced much criticism (see especially Shultz $[16,22,102]$ ) and a problem already experienced in similar analyses 
including extant material is the fact that many putative chelicerate plesiomorphies are unrecognizable among Pycnogonida. This has led to analyses optimizing these characters as autapomorphic for Xiphosura. We may list in this context the presence of a carapace pleural margin (Ch. 3), a cephalic doublure (Ch. 9), a posteroventraly directed mouth (Ch. 11), a well developed post-anal telson (Ch. 23), presence of gnathobases (Ch. 47) and presence of endosternal suspensors of opisthosomal somites I and II (Ch. 125). All these characters are not clearly applicable to, or else wholly absent from, Pycnogonida. However they are (in part) evident in potential chelicerate outgroups ('trilobitomorphs', 'great appendage' arthropods) among the early Paleozoic arthropods [103]. Integration of paleontological data will be crucial for solving the problem of character polarity within Chelicerata - and hopefully arachnid monophyly too - but this goes beyond the scope of the present study. We refer the reader to Dunlop [104] for a review of possible chelicerate origins and to our character statements (Additional file 5), in which paleontological information is discussed where relevant.

\section{Conclusions}

Previous studies combining ribosomal sequences and morphology recovered topologies similar to those morphological analyses which yielded taxa such as Haplocnemata and Acari. Comparing the results of the methods for molecular homology assessment employed here, we conclude that the apparent stability of the clades noted above in total evidence analyses is better explained as the byproduct of the way the molecular homology was established using the instrumentalist approach implemented in POY. Constraining the analysis by a priori homology assessment is defended as a way of maintaining the severity of the test when adding new data to the analysis. Although the strength of this methodology is that it retains phylogenetic information from regions usually discarded in an exclusively static homology framework, it still has the inconvenience of being uninformative on the effect of alignment ambiguity on resampling methods of clade support estimation. Finally, the most notable result of our analysis is further evidence for a strong molecular signal supporting Solifugae + Acariformes. Morphological apomorphies for this clade - for which we here adopt the name Poecilophysidea - include reduction of the proximal cheliceral podomere, medial abutting of the leg coxae, loss of sperm nuclear membrane, and presence of differentiated germinative and secretory regions in the testis delivering their products into a common lumen. This last character in particular has been widely overlooked in recent morphological studies concerning chelicerate phylogeny.

\section{Additional material}

\begin{abstract}
Additional file 1: Sampling data and taxonomy. The table indicate the taxonomy and collection information for the species newly sequenced and associated accession number for the MZUSP collection.

Additional file 2: Secondary structure alignments. Two FASTA files containing the secondary structure alignments of $18 \mathrm{~S}$ and $28 \mathrm{~S}$ are provided, along with two notations marks, a pairing mask with signals such "( )", " \{\} ", and " $<>$ " for paired sites, indicating the pair members; ".", for unpaired sites and "**", for regions of ambiguous alignment. The other mask indicates secondary structures as labeled in the Fig. 2, 3.

Additional file 3: Monitoring the convergence of MCMC in Bayesian analyses. Plotings of the $L n L$ of the stationary phase of each one of the models along with a comparison of parameters values obtained from the two independent runs using Gelman's statistic [105] are provided.

Additional file 4: POY imputs. Fasta files including all the regions of ambiguous alignment are provided.

Additional file 5: Morphological characters statements. The file provided include statements of the 178 morphological characters used in the combined phylogenetic analyses and gathered along the present study.

Additional file 6: Morphological datasets. Two data matrices are provided, that produced by scoring character statements gathered along the present study (Matrix A) and those enunciated by Shultz [22] (Matrix B)

Additional file 7: Tables with ILD metrics values for analysis employing direct optimization. The file contains ILD metrics values for the standard and constrained analysis of molecular data alone, and combined analysis of molecular data and morphological data matrices $A$ and $B$.
\end{abstract}

\section{Acknowledgements}

This article is part of Almir R. Pepato's PhD thesis developed at the Universidade de São Paulo and supported by FAPESP (05/03458-1). Highperformance cluster infrastructure was provided by the Molecular Systematic Laboratory at the Department of Zoology - IB/USP, financed by FAPESP (Proc. Nos. 2003/10335-8, 2004/09961-4, 2005/01299-3, and 2008/06604-7). Authors gratefully acknowledge Dr. Fernando Portella de Luna Marques (IBUSP) for the constant assistance concerning the analysis implementation. Special thanks are due to Dr. Karl Kjer (Rutgers University, New Jersey), Dr. Leandro Cézane de Souza Assis (IBUSP), Bsc. Maxmiliano Maronna (IBUSP), Dra. Grace Wyngaard (James Madison University, Harrisonburg), Dr. Gilberto José de Moraes (ESALQ-USP), Dr. Carlos Holger Wenzel Flechtmann (ESALQUSP), and Dr. Márcio Bernardino da Silva (UFPB) for reading early drafts of this study and providing very useful suggestions on the study directions and to Dr. Eduardo Gorab (IBUSP) for suggestions on secondary structure issues. We also thank three anonymous referees for valuable comments on earlier versions of the manuscript.

\section{Author details}

'Departamento de Zoologia, Instituto de Biociências, Universidade de São Paulo, Rua do Matão, travessa 14, 321, 05508-900, São Paulo, Brazil. ${ }^{2}$ Museum für Naturkunde, Leibniz Institute for Research on Evolution and Biodiversity at the Humboldt University Berlin, Invalidenstrasse 43, 10115 Berlin, Germany.

\section{Authors' contributions}

ARP designed this study, carried out the molecular alignment employing the rRNA secondary structure, conducted Bayesian and POY analyses,

participated in the scoring and elaboration of morphological matrices and drafted the manuscript. CEFR participated in the data acquisition, in study design and helped to draft the manuscript. JAD elaborated the morphological character statements, participated in the scoring of morphological matrices, wrote substantial portion of the discussion section and helped to draft the manuscript. All authors read and approved its final version. 
Received: 15 December 2009 Accepted: 2 August 2010

Published: 2 August 2010

\section{References}

1. Evans GO: Principles of Acarology Wallingford, C.A.B. International 1992.

2. Harvey MS: The neglected cousins: what do we know about the smaller arachnid orders? J Arachnol 2002, 30:357-372.

3. Halliday RB: Mites of Australia, a Checklist and Bibliography Melbourne, CSIRO Publishing 1998

4. Lindquist EE: Current theories on the evolution of major groups of Acar and on their relationships with other groups of Arachnida, with consequent implications for their classificaton. Acarology VI New York, John Wiley \& SonsGriffiths DA, Bowman CE 1984, 1:28-62

5. Alberti $\mathrm{G}$ : On some fundamental characteristics in acarine morphology. Atti Accad Naz Ital Entomol 2006, 2005:315-360.

6. Dunlop JA, Alberti G: The affinities of mites and ticks: a review. J Zool Syst Evol Res 2007, 46:1-18.

7. Dunlop JA, Penney OD, Tetlie E, Anderson LI: How many species of fossil arachnids are there? J Arachnol 2008, 36:267-272.

8. Masta SE, Longhorn SJ, Booreb JL: Arachnid relationships based on mitochondrial genomes: Asymmetric nucleotide and amino acid bias affects phylogenetic analyses. Mol Phylogenet Evol 2009, 50:117-128.

9. Wheeler WC, Hayashi CY: The phylogeny of the extant chelicerate orders. Cladistics 1998, 14:173-192.

10. Giribet G, Edgecombe GD, Wheeler WC, Babbitt C: Phylogeny and systematic position of Opiliones: a combined analysis of chelicerate relationships using morphological and molecular data. Cladistics 2002, 18:5-70.

11. Klompen H, Lekveishvili M, Black WC IV: Phylogeny of parasitiform mites (Acari) based on rRNA. Mol Phylogenet Evol 2007, 43:936-951.

12. Weygoldt P, Paulus HF: Untersuchungen zur Morphologie, Taxonomie und Phylogenie der Chelicerata. 2. Cladogramme und die Entfaltung der Chelicerata. J zoolog syst evol res 1979, 17:177-200.

13. van der Hammen L: A new classification of Chelicerata. Zool meded 1977, 51:307-319.

14. van der Hammen L: An introduction to comparative arachnology Leiden, SPB Academic Publishing 1989

15. Shultz JW: Morphology of locomotor appendages in Arachnida: evolutionary trends and phylogenetic implications. Zool J Linn Soc 1989, 97:1-56.

16. Shultz JW: Evolutionary morphology and phylogeny of Arachnida. Cladistics 1990, 6:1-38.

17. Dubinin WB: New system of the superclass Chelicerata. Byull Mosk Obshch Ispyt, priorody, biol 1957, 62:25-33, [in Russian with English summary]

18. Dunlop JA: Evidence for a sister group relationship between Ricinulei and Trigonotarbida. Bull Br Arachnol Soc 1996, 10:193-204.

19. Dunlop JA, Kamenz C, Talarico G: A fossil trigonotarbid arachnid with a ricinuleid-like pedipalpal claw. Zoomorphology 2009, 128:305-313.

20. van der Hammen L: Comparative studies in Chelicerata. I. The Cryptognomae (Ricinulei, Architarbi and Anactinotrichida). Zool verh 1979, 174:1-62.

21. Alberti $G$, Peretti AV: Fine structure of male genital system and sperm in Solifugae does not support a sister-group relationship with Pseudoscorpiones (Arachnida). J Arachnol 2002, 30:268-274.

22. Shultz JW: A phylogenetic analysis of the arachnid orders based on morphological characters. Zool J Linn Soc 2007, 150:221-265.

23. Regier JC, Shultz JW, Zwick A, Hussey A, Ball B, Wetzer R, Martin JW, Cunningham CW: Arthropod relationships revealed by phylogeneomic analysis of nuclear protein-coding sequences. Nature 2010, 463:1079-1083

24. Dabert M, Witalinski W, Kazmierski A, Olszanowski Z, Dabert J: Molecular phylogeny of acariform mites (Acari, Arachnida): Strong conflict between phylogenetic signal and long-branch attraction artifacts. Mol Phylogenet Evo Available online 6 January 2010

25. Giribet $G$, Ribera $C$ : The position of arthropods in the animal kingdom: $A$ search for a reliable outgroup for internal arthropod phylogeny. Mol Phylogenet Evol 1998, 9:481-488.

26. Maxmen A, Browne WE, Martindale MQ, Giribet G: Neuroanatomy of sea spiders implies an appendicular origin of the protocerebral segment. Nature 2005, 437:1144-1148.
27. Bitsch J, Bitsch C: The segmental organization of the head region in Chelicerata: a critical review of recent studies and hypotheses. Acta Zool (Stockholm) 2007, 88:317-335.

28. Damen WGM, Hausdorf M, Seyfarth E-A, Tautz D: A conserved mode of head segmentation in arthropods revealed by the expression of Hox genes in a spider. Proc Natl Acad Sci USA 1998, 95:10665-10670.

29. Telford MJ, Thomas RH: Expression of homeobox genes show chelicerate arthropods retain their deutocerebral segment. Proc Natl Acad Sci USA 1998, 95:10671-10675.

30. Manuel M, Jager M, Murienne J, Clabaut C, Le Guyader H: Hox genes in sea spiders (Pycnogonida) and the homology of arthropod head segments. Dev genes evol 2006, 216:481-491.

31. Brenneis G, Ungerer P, Scholtz G: The chelifores of sea spiders (Arthropoda, Pycnogonida) are the appendages of the deutocerebral segment. Evolut develop 2008, 10:717-724

32. Norton RA, Kethley JB, Johnston DE, OConnor BM: Phylogenetic perspectives on genetic systems and reproductive modes of mites. Evolution and diversity of sex ratio in insects and mites New York, Chapman \& HallWrensch DL, Ebbert MA 1993, 8-99.

33. Lindquist EE, Krantz GW, Walter DE: Classification. A Manual of Acarology Lubbock, Texas Tech University PressKrantz GW, Walter DE 2009, 97-103.

34. Walter DE: Suborder Endeostigmata. A Manual of Acarology Lubbock, Texas Tech University Presskrantz GW, Walter DE 2009, 421-429.

35. Giribet $G$, Carranza S, Baguñà J, Riutort M, Ribera C: First molecular evidence for the existence of a Tardigrada + Arthropoda clade. Mol biol evol 1996, 13:76-84

36. Otto J, Wilson K: Assessment of the usefulness of ribosomal $18 \mathrm{~S}$ and mitochondrial $\mathrm{CO}$ sequences in Prostigmata phylogeny. Acarology: Proceedings of the 10th International Congress Coll of M. J. Melbourne, CSIRO PublishingHalliday RB, Walter DE, Proctor HC, Norton RA 2001, 100-109.

37. Whiting MF, Carpenter JM, Wheeler QD, Wheeler WC: The Strepsiptera problem: Phylogeny of the holometabolous insect orders inferred from $18 \mathrm{~S}$ and $28 \mathrm{~S}$ ribosomal DNA sequences. Syst Biol 1997, 46:1-68.

38. Gutell RR, Larsen N, Woese CR: Lessons from an evolving rRNA: $16 \mathrm{~S}$ and $23 \mathrm{~S}$ rRNA structures from a comparative perspective. Microbiol mol biol rev 1994, 58:10-26.

39. Nagaswamy U, Voss N, Zhang Z, Fox GE: Database of noncanonical base pairs found in known RNA structures. Nucleic Acids Res 2000, 28:356-357.

40. Wuyts J, De Rijk P, Van de Peer Y, Pison G, Rousseeuw P, De Wachter R: Comparative analysis of more than 3000 sequences reveals the existence of two pseudoknots in area V4 of eukaryotic small subunit ribosomal RNA. Nucleic Acids Res 2000, 28:4698-4708

41. Gutell RR, Lee JC, Cannone JJ: The accuracy of ribosomal RNA comparative structure models. Curr Opin Struct Biol 2002, 12:301-310

42. Kier KM: Use of rRNA secondary structure in phylogenetic studies to identify homologous positions: An example of alignment and data presentation from the frogs. Mol Phylogenet Evol 1995, 4:314-330.

43. Hall TA: BioEdit: a user-friendly biological sequence alignment editor and analysis program for Windows 95/98/NT. Nucleic Acids Symp Ser 1999, 41.95-98.

44. Wuyts J, Perrière G, van der Peer $Y$ : The European ribosomal RNA database. Nucleic Acids Res 2004, 32:D101-D103.

45. Schnare MN, Damberger SH, Gray MW, Gutell RR: Comprehensive comparison of structural characteristics in eukaryotic cytoplasmic large subunit (23S-like) ribosomal RNA. J mol biol 1996, 256:701-719.

46. Rix $M$, Harvey $M$, Roberts J: Molecular phylogenetics of the spider family Micropholcommatidae (Arachnida: Araneae) using nuclear rRNA genes (18 S and 28S). Mol Phylogenet Evol 2008, 46:1031-1048.

47. Zuker M: Mfold web server for nucleic acid folding and hybridization prediction. Nucleic Acids Res 2003, 31:3406-3415.

48. Hofacker IL, Fekete M, Stadler PF: Secondary structure prediction for aligned RNA Sequences. J mol biol 2002, 319:1059-1066.

49. Gillespie JJ: Characterizing regions of ambiguous alignment caused by the expansion and contraction of hairpin-stem loops in ribosomal RNA molecules. Mol Phylogenet Evol 2004, 33:936-943.

50. Cannone JJ, Subramanian S, Schnare MN, Collett JR, D'Souza LM, Du Y, Feng B, Lin N, Madabusi LV, Muller KM, Pande N, Shang Z, Yu N, Gutell RR: The Comparative RNA Web (CRW) Site: An online database of comparative sequence and structure information for ribosomal, intron and other RNAs. BMC Bioinf 2002, 3:15. 
51. Wheeler WC, Honeycutt RL: Paired sequence difference in ribosomal RNAs: Evolutionary and phylogenetic implications. Mol Biol Evol 1988, 5.90-96.

52. PHASE : a software package for Phylogenetics and Sequence Evolution. [http://www.bioinf.manchester.ac.uk/resources/phase/].

53. Savill N, Hoyle D, Higgs P: RNA sequence evolution with secondary structure constraints: Comparison of substitution rate models using maximum likelihood methods. Genetics 2001, 157:399-411.

54. Nylander JAA, Ronquist F, Huelsenbeck JP, Nieves-Aldrey J: Bayesian phylogenetic analysis of combined Data. Syst Biol 2004, 53:47-67.

55. Posada D: jModelTest: Phylogenetic Model Averaging. Mol Biol Evol 2008, 25:1253-1256

56. Gillespie JJ, Yoder MJ, Wharton RA: Predicted secondary structures for 28 $\mathrm{S}$ and $18 \mathrm{~S}$ rRNA from Ichneumonoidea (Insecta: Hymenoptera: Apocrita): Impact on sequence alignment and phylogeny estimation. $J$ mol evol 2005, 61(1):114-137.

57. Rambaut A, Drummond AJ: Tracer, MCMC Trace Analysis Tool Version v1.4.1. 2003 [http://beast.bio.ed.ac.uk/Tracer].

58. Varón A, Vinh LS, Bomash I, Wheeler WC: POY 4.0 Beta 2398. American Museum of Natural History 2007 [http://research.amnh.org/scicomp/projects/ poy.php].

59. Goloboff PA, Farris JS, Nixon KC: TNT, a free program for phylogenetic analysis. Cladistics 2008, 24:774-786

60. Wheeler WC: Optimization alignment: the end of multiple sequence alignment in phylogenetics? Cladistics 1996, 12:1-9.

61. Wheeler WC: Sequence alignment, parameter sensitivity, and the phylogenetic analysis of molecular data. Syst Biol 1995, 44:321-331.

62. Giribet G: Stability in phylogenetic formulations, and its relationship to nodal support. Syst Biol 2003, 52:554-564.

63. Grant T, Kluge AG: Stability, sensitivity, science, and heurism. Cladistics 2005, 21:597-604.

64. Mickevich MF, Farris JS: The implications of congruence in Menidia. Syst Zool 1981, 27:143-158.

65. Jordal B, Gillespie JJ, Cognato Al: Secondary structure alignment and direct optimization of $28 \mathrm{~S}$ rDNA sequences provide limited phylogenetic resolution in bark and ambrosia beetles (Curculionidae: Scolytinae). Zool Scr 2008, 37:43-56.

66. Goloboff PA: Analyzing large data sets in reasonable times: Solutions for composite optima. Cladistics 1999, 15(4):415-428.

67. Giribet G: Efficient tree searches with available algorithms. Evol Bioinform 2007, 3:1-16.

68. Gutell RR, Cannone JJ, Shang Z, Du Y, Serra MJ: A story: Unpaired adenosine bases in ribosomal RNAs. J Mol Biol 2000, 304:335-354.

69. Ogden TH, Rosenberg MS: Alignment and topological accuracy of the direct optimization approach via POY and traditional phylogenetics via Clustal W + PAUP*. Syst Biol 2007, 56:182-193.

70. Lehtonen S: Phylogeny estimation and alignment via POY versus Clustal + PAUP*: A response to Ogden and Rosenberg (2007). Syst Biol 2008, 57(4):653-657.

71. Kjer KM, Gillespie JJ, Ober KA: Opinions on multiple sequence alignment, and an empirical comparison of repeatability and accuracy between POY and structural alignments. Syst Biol 2007, 56:133-146.

72. de Pinna MGG: Concepts and tests of homology in the cladistic paradigm. Cladistics 1991, 7:367-394.

73. Assis LCS, Brigandt I: Homology: Homeostatic Property Cluster Kinds in Systematics and Evolution. Evol Biol 2009, 36:248-255.

74. Morrison DA: Multiple sequence alignment for phylogenetic purposes. Aust Syst Bot 2006, 19:479-539.

75. Giribet G, Wheeler W: On Gaps. Mol Phylogenet Evol 1999, 13:132-143.

76. Lee MSY: Unalignable sequences and molecular evolution. Trends Ecol Evol 2001, 16:681-685.

77. Wheeler WC, Giribet G: Phylogenetic hypotheses and the utility of multiple sequence alignment. Perspectives on Biological Sequence Alignment Berkeley, University of California PressRosenberg M 2009, 95-104

78. Wheeler WC, Aagesen L, Arango CP, Faivovich J, Grant T, D'Haese D, Janies D, Smith WL, Varon A, Giribet G: Dynamic homology and phylogenetic systematics: a unified approach using POY. 1 New York, American Museum of Natural History 2006.

79. Rieppel $\mathrm{O}$ : The nature of parsimony and instrumentalism in systematics. J Zool Syst Evol Res 2007, 45:177-183.
80. Simmons MP: Independence of alignment and tree search. Mol Phylogenet Evol 2004, 31:874-879.

81. Wortley AH, Scotland RW: The effect of combining molecular and morphological data in published phylogenetic analyses. Syst Biol 2006, 55:677-685.

82. Vogt L: The unfalsifiability of cladograms and its consequences. Cladistics 2008, 24:62-73

83. Kluge AG: On the deduction of species relationships: a précis. Cladistics 2003, 19:233-239.

84. Hickson RE, Simon C, Perrey SW: The performance of several multiplesequence alignment programs in relation to secondary-structure features for an rRNA sequence. Mol biol evol 2000, 17:530-539.

85. Swain TD, Taylor DJ: Structural rRNA characters support monophyly of raptorial limbs and paraphyly of limb specialization in water fleas. Proc $R$ Soc Lond B Biol sci 2003, 270:887-896.

86. Gorab E, de Lacoba MG, Botella LM: Structural constraints in expansion segments from a midge 26 S rDNA. J Mol Evol 1995, 41:1016-1021

87. Redelings BD, Suchard MA: Joint Bayesian estimation of alignment and phylogeny. Syst Biol 2005, 54:401-418.

88. Kamenz C, Dunlop JA, Scholtz G, Kerp H, Hass H: Microanatomy of Early Devonian book lungs. Biol lett 2008, 4:212-215.

89. Klann AE, Bird T, Peretti AV, Gromov AV, Alberti G: Ultrastructure of spermatozoa of solifuges (Arachnida, Solifugae): Possible characters for their phylogeny? Tissue Cell 2009, 41:91-103.

90. Dunlop JA: Poecilophysidea: a forgotten arachnid order illustrating a forgotten phylogenetic hypothesis. Newsl Br Arachnol Soc 1999, 85:4-6.

91. Cambridge OP: On a new order and some new genera of Arachnida from Kerguelen's Land. Proc Zool Soc Lond 1876, 258-265.

92. Banks $\mathrm{N}$ : The Acarina or mites. A review of the group for the use of economic entomologists. Rep USDA 1915, 108:1-142.

93. Grandjean F: Un acarien synthetique: Opilioacarus segmentatus With. Bull Soc Hist Nat Afr Nord 1936, 27:413-444.

94. Grandjean F: Etude sur les palaeacaroides (Acariens, Oribates). Mem Mus Natl Hist Nat Ser A, Zool 1954, 7:179-274.

95. Firstman BF: The relationship of the cheliceral arterial system to the evolution of the endosternite. J Arachnol 1973, 1:1-54.

96. van der Hammen L: Comparative studies in Chelicerata. II. Epimerata (Palpigradi and Actinotrichida). Zool verh 1982, 196:1-70.

97. Dunlop JA, Arango CP: Pycnogonid affinities: a review. J Zool Syst Evol Res 2005, 43:8-21.

98. Yoshikura M: Comparative embryology and phylogeny of Arachnida. Kumamoto I sci Biol 1975, 12:71-142.

99. Alberti G, Kaiser T, Löwenfeld IK: Zur Feinstruktur und Funktion de Ventralsäcken und vergleichbarer Organe bei Spinnentiere (Arachnida). Verh Dtsch Zool Ges 1992, 85:197.

100. Bartsch I: Porohalacarus alpinus (Thor) (Halacaridae, Acari), ein morphologischer Vergleich mit marinen Halacariden nebst Bemerkungen zur Biologie dieser Art. Entomol tidskr 1973, 74:116-123.

101. Alberti G: Zur Feinstruktur und Funktion der Genitalnäpfe von Hydrodroma despiciens (Hydrachnellae, Acari). Zoomorphologie 1977, 87:155-164.

102. Shultz JW: Gross muscular anatomy of Limulus polyphemus (Xiphosura, Chelicerata) and its bearing on evolution in the Arachnida. J Arachnol 2001, 29:283-303.

103. Cotton TJ, Braddy SJ: The phylogeny of arachnamorph arthropods and the origin of the Chelicerata. Trans R Soc Edinb Earth sci 2004, 94:169-193.

104. Dunlop JA: New ideas about the euchelicerate stem-lineage. Acta Zool Bulg Suppl 2006, 1:9-23.

105. Miller RE, McDonald JA, Manos PS: Systematics of Ipomoea subgenus Quamoclit (Convolvulaceae) based on ITS sequence data and a Bayesian phylogenetic analysis. Am J Bot 2004, 91:1208-1218.

doi:10.1186/1471-2148-10-235

Cite this article as: Pepato et al:: Phylogenetic position of the acariform mites: sensitivity to homology assessment under total evidence. $B M C$ Evolutionary Biology 2010 10:235. 